\title{
EL DERECHO CONSTITUCIONAL ANTE LA ERA DE ULTRÓN: LA INFORMÁTICA Y LA INTELIGENCIA ARTIFICIAL COMO OBJETO CONSTITUCIONAL
}

\author{
Juan Francisco Sánchez Barrilao \\ doi: 10.18543/ed-64(2)-2016pp225-258
}

\begin{abstract}
Sumario: I. Introducción: ANTE la era de Ultrón. II. El Derecho CONSTITUCIONAL HOY. III. SOBRE LA CONTINGENCIA Y LA INCERTIDUMBRE EN EL DERECHO. IV. LA INFORMÁTICA COMO OBJETO ESPECÍFICO DEL DERECHO CONSTITUCIONAL: DE LA MERA PROTECCIÓN DE DATOS A LA LIBERTAD INFORMÁTICA. V. LA INFORMÁTICA COMO TRANSFORMACIÓN DE LO CONSTITUCIONAL. VI. LA INFORMÁTICA COMO CAUSA DE CONFLICTOS CONSTITUCIONALES. VII. DE VUELTA A LA INFORMÁTICA COMO OBJETO CONSTITUCIONAL: DE LA PREVISIÓN DE NUEVOS LÍMITES CONSTITUCIONALES EN RELACIÓN CON LA INFORMÁTICA, A LA PROMOCIÓN CONSTITUCIONAL DE LA INFORMÁTICA. VIII. El DERECHO CONSTITUCIONAL EN los tiempos del Google SELF-DRIVING CAR. IX. CONSIDERACIONES FINALES SOBRE LA INTELIGENCIA ARTIFICIAL Y EL DERECHO CONSTITUCIONAL.
\end{abstract}

\section{INTRODUCCIÓN: ANTE LA ERA DE ULTRÓN*}

Hace poco Stephen Hawking advertía públicamente en una entrevista del riesgo que para la humanidad supondría, al tiempo, la inteligencia artificial';

* Por la presente agradezco a A Pérez Miras las notables y numerosas sugerencias y correcciones que me ha planteado tras la lectura de una primera versión de este trabajo; y ya en Granada, cómo no, a E. Guillén López y M. Azpitarte Sánchez, siempre atentos y dispuestos a compartir (y discutir) ideas sobre lo que escribo. Esta investigación, por otra 
no es realmente un juicio original, pues en gran medida el físico británico venía a amplificar y publicitar las tesis de Nick Bostrom (Director del Future of Humanity Institute, Universidad de Oxford), quien considera la inteligencia artificial como uno de los principales riesgos para la supervivencia de la especie humana al no resultar garantizado que ésta sea capaz de controlar las máquinas inteligentes que a buen seguro se harán en el futuro a fin de propiciar (paradójicamente) un mejor mañana para los humanos ${ }^{2}$. La imagen, entre otras, de un HAL-9000 (2001 A Space Odyssey), de Skynet (The Terminator), de VIKI (I, Robot) o, cómo no, de la misma Matrix (The Matrix) ${ }^{3}$, toma cuerpo intelectual así en el corazón mismo de una sociedad tecnificada, globalizada y del riesgo ${ }^{4}$ y en la que el desarrollo de la informática ha venido, precisamente, a catalizar aquélla dado que motor del avance científico (en cualquiera de sus ramas), de la aparición de nuevos y artificiales peligros, y de la intercomunicación mundial (sociedad de la información, o digital) ${ }^{5}$.

Es así que, en principio, tal recelo a la inteligencia artificial y a la informática quepa presentársenos hoy como una reformulación o actualización digital del clásico mito de Prometeo, y de su refundición romántica luego en el síndrome del Frankenstein de Mary Shelley, en los que el progreso de

parte, se ha desarrollado en el marco del Proyecto de Investigación DER2013-42960-P («La dimensión constitucional del proceso de integración europea en el contexto de la globalización»), y del que soy investigador principal.

${ }^{1}$ En <http://www.abc.es/tecnologia/informatica-software/20141202/abci-stephenhawking-peligros-inteligencia-201412021837.html $>$ (05/03/2016). De otra parte, para una primera aproximación a la inteligencia artificial, vid. p.e. CHACÓN RANGEL, J.G., Smith Flórez Fuentes, A. y Rodríguez FernÁndeZ, J.E., «La inteligencia artificial y sus contribuciones a la física médica y la bioingeniería», Mundo FESC Vol. 1/9 (2015): 6063.

2 Bostrom, N., Superintelligence: Paths, Dangers, Strategies (Oxford: Oxford University Press, 2014).

3 Si bien ésta se presenta más como una red o sistema, que como una máquina concreta; sería así, más bien, 01 o Zero-One, dado que ciudad-máquina origen de la revolución de las máquinas frente a los humanos, de la extensión al tiempo de la ulterior red de Matrix, y en donde además se encuentra Deus ex machina, como máquina que gobierna Matrix y sede del Arquitecto (The Animatrix y The Matrix Revolutions). Por otra parte no se ha de olvidar cómo Matrix trasciende del riesgo mismo y la sumisión que para la humanidad supone ésta, por cuanto que filosóficamente entronca con el mundo de la realidad, los sueños, la ficción y la alineación humana.

4 Ya, Sánchez Barrilao, J.F., De la ley al reglamento delegado (Deslegalización, acto delegado y transformaciones del sistema de fuentes) (Pamplona: Aranzadi/Thomson Reuters, 2015), 228-232.

5 Vid. Silva Robles, C., Jiménez Marín, G. y Elías Zambrano, R., «De la sociedad de la información a la sociedad digital: Web 2.0 y redes sociales en el panorama mediático actual»,F@ro: Revista teórica del Departamento de Ciencias de la Comunicación 15 (2012). 
la ciencia y la tecnología, recuérdese, desembocaba en la expiación de los hombres por creerse Dioses ${ }^{6}$. Pero puede que el dicho recelo responda también a la necesidad de comprender e intentar dominar, o al menos controlar, una compleja realidad en constante y acelerado cambio y transformación a la sombra de hardware, software y redes que hacen que el presente (el mismo instante...) sea aún más confuso y perecedero con relación a un futuro casi inmediato y desconocido; y un futuro, además, soñado y diseñado por idealistas e ingenieros, pero protagonizado, a la postre, por poderes e individuos (y grupos) que actúan al impulso de unos y otros intereses e ideologías?.

Por tanto, no es que estemos realmente ante un problema nuevo; si acaso ante una muy peculiar manifestación del desarrollo tecnológico, en su conjunto (sociedad de la información, nuevamente), y al hilo del actual mundo globalizado y del riesgo en el que vivimos (según se acaba de señalar). Y con esto que la tecnología, y a su vera o vanguardia la informática, entronquen con las misiones que al Derecho constitucional se le reconoce ya en estos tiempos, dado que ambivalentes factores de riesgo y de progreso: de esta forma, y desde hace bastantes años, por ejemplo, la protección de la intimidad y de los datos personales ante la informática (art. 18.4 CE) ${ }^{8}$; o más recientemente, y en Derecho constitucional comparado, el reconocimiento de cierto derecho de las personas a participar en el progreso informático (así, arts. 16.2 y 17.2 Constitución de 2008 de la República de Ecuador; art. 63

${ }^{6}$ Sobre el primero, vid. SAlmoni, F., Le norme tecniche (Milano: Giuffrè Editore, 2001): 8- 15.; y acerca del segundo, LóPez CEREzo, J.A. y SÁnChEz Ron, J.M., «Ciencia, tecnología, sociedad y cultura en el cambio de siglo», en AA.VV. Ciencia, tecnología, sociedad y cultura en el cambio de siglo (Madrid: Biblioteca Nueva/Organización de Estados Iberoamericanos, 2001), 15 y 16.

7 De este modo que las relaciones de poder sigan y seguirán existiendo, y con ello el interrogante mismo del por qué obedecer y hasta dónde hacerlo en este nuevo contexto en el que la informática será instrumento, objeto e incluso, hipotéticamente, sujeto de poder; y por tanto que aquélla, finalmente, se nos presente como problema específico para el Derecho constitucional, en cuanto que éste se proyecta y explica en relación al poder y en garantía de la libertad de los individuos. Ya, sobre el Derecho constitucional y las relaciones de poder, $c f r$. Garrorena Morales, Á. «Cuatro tesis y un corolario sobre el Derecho constitucional», Revista Española de Derecho Constitucional 51 (1997), 40; y a la vista ahora del contexto globalizado en el que nos hayamos desde hace tiempo (y sus consecuencias), vid. SÁnchez BARRILAO, J.F., «Sobre la Constitución normativa y la globalización», Revista de la Facultad de Derecho de la Universidad de Granada 7 (2004), 241 y 242.

${ }^{8}$ Sin perjuicio de volver a ello más adelante, vid. SEMPERE Rodríguez, C., «Artículo 18: Derecho al honor, a la intimidad y a la propia imagen», en AA.VV. Comentarios a la Constitución Española de 1978 (II) (Madrid: Cortes Generales / Editoriales de Derecho Reunidas, 1997), en particular sobre el art. 18.4, 446 y ss. 
Constitución de la República Dominicana de 2010; o art. 6 Constitución Mexicana, tras su reforma de 2013) ${ }^{9}$.

Entonces, ¿en dónde residiría lo auténticamente novedoso que plantea la señalada desconfianza sobre la inteligencia artificial hoy? Tal vez no sea sino una vuelta de tuerca más en nuestra toma de consciencia de la dificultad misma (o el propio grado de dificultad) sobre cómo decidir al respecto del progreso humano y del riesgo que con carácter general éste supone, sin embargo, para la humanidad, así como del progreso y del riesgo informático en particular y especialmente. En tal sentido, y volviendo al cine de ciencia ficción (por su capacidad de imaginar futuros alternativos, mas sin dejar de reconocer que la realidad supera la ficción) ${ }^{10}$, al margen de mostrar hipotéticos riesgos y desastres para la humanidad originados por el progreso tecnológico e informático (a cuál más espectaculares y tremebundos), éste nos ha dado también la posibilidad, como público, de ser testigos incrédulos de intensos debates entre los protagonistas de los films en relación con la complejidad de tomas de decisiones en torno a la ciencia, la tecnología y la informática: de este modo, por ejemplo, el debate de Tony Stark (Iron Man) con Bruce Banner (Hulk) sobre la conveniencia de conectar el Cetro de Loki con el ordenador J.A.R.V.I.S., ante el peligro de una invasión (extraterrestre) por los Chitauris, para luego generarse un nuevo peligro de manos de la aparición del androide Ultrón, pues éste cree necesario eliminar la humanidad para salvar la Tierra; luego, cómo Steve Rogers (el Capitán América) exige responsabilidad a Tony Stark y a Bruce Banner por su decisión autónoma (no colectiva), y el riesgo generado con carácter universal (por la aparición de Ultrón, claro); y de cómo, y sin embargo (y en una especie de deja $v u$ ), Tony Stark vuelve a debatir (discutiendo ya) con Bruce Banner la posibilidad de volver a repetir el experimento (jvolver a conectar a J.A.R.V.I.S.!), bajo el paradigma de que el riesgo tecnológico únicamente puede ser salvado por el progreso tecnológico, y despreciando en su decisión cualquier otra conside-

9 Arts. 16.2 y 17.2 Constitución ecuatoriana, reconociendo expresamente un derecho de «acceso universal a las tecnologías de información y comunicación», a la vez que el Estado ha de fomentar «la pluralidad y la diversidad en la comunicación» para lo cual ha de facilitar «el acceso universal a las tecnologías de información y comunicación en especial para las personas y colectividades que carezcan de dicho acceso o lo tengan de forma limitada». Art. 63 Constitución dominicana, conforme al cual el «Estado garantiza servicios públicos de [...] redes de bibliotecas y de informática, con el fin de permitir el acceso universal a la información». Y art. 6 Constitución mexicana, en virtud del cual el «Estado garantizará el derecho de acceso a las tecnologías de la información y comunicación, [..] incluido el de banda ancha e internet».

10 P.e. Muñoz De Baena y Simón, J.L., «Utopías, distopías, deicidios: el cine de ciencia ficción», en AA.VV. Derecho y cine: el Derecho visto por los géneros cinematográficos (Valencia: Tirant lo Blanch, 2008), 267-295. 
ración y sujetos en razón a que, a fin de cuentas, ambos son «científicos locos $»{ }^{11}$. Claro que la impetuosidad de Tony Stark resulta más atractiva para el público que la bisoñez de Steve Rogers, pero también es más prepotente ${ }^{12}$. El respeto que Steve Rogers exige a Tony Stark en relación con los demás (y en especial al grupo) es la base del principio democrático: el respeto así a que la decisión se tome colectivamente, y no sólo por unos pocos (y científicos), y más cuando la decisión puede afectar dañinamente a todo el colectivo; no se olvide, «[e]l error en la justificación del Derecho sólo es razonable [democráticamente], si el que lo produce es el que ha de soportarlo» ${ }^{13}$.

Pero también de interés para estas páginas (y dándole título) es la propia aparición en escena del mismo Ultrón, en cuanto que nuevo sujeto inteligente e independiente a los humanos, además de creador de nuevas entidades ${ }^{14}, \mathrm{y}$ por tanto, y al tiempo, generador de un riesgo (y un ulterior daño) autónomo a los humanos y no controlable ya por ellos. No es sólo, entonces, la inteligencia y la acción humana la que generaría peligros artificiales (frente a los de la naturaleza y los del entero cosmos), sino una potencial inteligencia artificial como fuente, a su vez, de riesgos singulares, de nuevas inteligencias artificiales, incluso. ¿Cómo y hasta dónde comprometernos, así, con la actuación de otra posible inteligencia no humana?

Por supuesto que la más arriba referida consciencia sobre el riesgo tampoco es desconocida en relación con la tecnología y al Derecho público en abstracto; de hecho, y al respecto de la biotecnología (en sentido amplio) se viene, desde hace años, planteando diversos procedimientos en los que integrarse más y mejor unos y otros, a la par que se han establecido nuevos principios jurídicos que permiten resolver conflictos, y se han aprobado no pocas normas sustantivas sobre las novedosas realidades que dicha tecnología

${ }^{11}$ Avengers: Age of Ultron (The Avengers 2), Whedon, J. (dir.) (Marvel Studios, 2015). Es así que la novedad de esta cinta frente a las anteriormente referidas sea el no limitarse a reflejar los riesgos que puede generar la inteligencia artificial al tiempo, sino en las dificultades propias de decidir inicialmente sobre ella, y sobre las responsabilidades generadas luego.

${ }^{12}$ De esta forma es que la novedad alcance a la consciencia misma de la inconsciencia con la que podría resolverse el riesgo de la inteligencia artificial.

${ }_{13}$ Cfr. López Calera, N.M., Introducción al estudio del Derecho (Granada, 1981), 134. Con todo, nos resulta extraño el que luego, tras este episodio, sea Tony Stark quien tome un rol más sujeto al poder público legitimado democráticamente, mientras que Steve Rogers reclama independencia de acción frente a éste; cómo no, Captain America: Civil War, Russo, A. y J. (dir.) (Marvel Studios, 2016).

${ }^{14}$ Sin duda es en los comics de Marvel donde mejor se advierte el desarrollo de cómo Ultrón genera, a la vez que es, inteligencia artificial en progreso, al auto-rediseñarse y actualizarse en distintas versiones de sí mismo. De interés, $<$ http://www.enciclopediamarvel.com/card/390> (25/08/2016). 
genera. Otra cosa es la adecuación o no de las respuestas abrigadas para las otras tecnologías al respecto de la informática y la inteligencia artificial ahora (según se acaba de señalar), además de que éstas pueden incidir o intermediar en las decisiones a adoptar sobre ellas mismas (dado que inteligencia externa y no humana); no en vano, la informática (y potencialmente la inteligencia artificial) ya es un instrumento en la toma de decisiones importantes, como precisamente se ha planteado en estos meses previos con relación al reparto de refugiados en Europa (y a fin de despolitizar, precisamente, tal decisión) ${ }^{15}$. La mencionada consciencia nos sitúa, por tanto, ante el reto del diseño de nuevos tiempos en los que la humanidad bien puede seguir progresando, o por el contrario retroceder e incluso desaparecer (¿la Era de Ultrón...?); y aunque el riesgo de la inteligencia artificial al final resultara ser simple exageración (en razón al estado actual y potencial futuro de la informática...), ¿no sería irresponsable arriesgarse a ello? ${ }^{16}$. Un reto, de este modo (y aun hipotético), no sólo tecnológico, sino ético, político y jurídico; un reto también, entendemos, constitucional ${ }^{17}$.

\section{EL DERECHO CONSTITUCIONAL HOY}

Ahora bien, el Derecho constitucional que ha de enfrentarse ya al reto de la informática (y a la inteligencia artificial) es el de un Derecho compuesto, complejo y más allá de la propia Constitución normativa-estatal, además de en evidente crisis sustantiva a la sombra de la globalización hoy. En cuanto a cómo en la actualidad se rompe la identificación entre Constitución y Derecho constitucional, en particular dado el modelo de Constitución estatal

${ }^{15}$ Cfr. $<$ https://euobserver.com/migration/133341> (05/05/2016).

${ }^{16}$ ForD, P., «La inteligencia artificial no destruirá a la humanidad, de momento (La creación de una IA auténtica podría acabar con el mundo, pero para eso primero tiene que ser posible)», MoyA, L. (trad.), MIT Technology Review, 12 de febrero de 2015, en $<$ https://www.technologyreview.es/informatica/46970/la-inteligencia-artificial-no-destruira-a-la/> (06/03/2016).

17 Ahora bien, previamente a aproximarnos constitucionalmente a la informática, consideramos oportuno señalar cómo la mayoría de las cuestiones constitucionalmente abiertas en torno a ésta giran hoy en su ordinaria dimensión instrumental, y ello ya sea generando conflictos con bienes de la más alta relevancia constitucional (protección de datos), o porque se plantee al servicio de éstos (p.e., voto electrónico). Pero también desde una dimensión instrumental de la propia informática respecto de la más amplia ciencia y tecnología, por cuanto que herramienta del resto de ramas científicas y tecnológicas, a salvo de la referida inteligencia artificial ya que objeto propio y autorreferencial de la misma informática; y de ahí, entonces, la especial dimensión de la inteligencia artificial para una necesaria caracterización constitucional de la informática (y al margen de los riesgos que sobre la misma se advertían al comienzo). 
y normativa asentada durante el pasado siglo ${ }^{18}$, la crisis que para el Estado supone la globalización (en tanto que ésta da lugar a una progresiva degradación de las fronteras soberanas de aquél) ${ }^{19}$, conlleva también la crisis misma de la Constitución normativa puesto que construida precisamente en torno a aquél; la incapacidad o, como poco, la limitación estatal generada por la globalización repercute negativamente en la propia efectividad normativa de la Constitución estatal, ya que ésta pasa a ser incapaz de ordenar totalmente la realidad político-jurídica del interior del Estado ${ }^{20}$; y si esto acontece con carácter general para todos los Estados (sin perjuicio, claro, de que el mayor peso y tamaño de éstos permita una mayor resistencia ante la globalización), más sucede al respeto de los Estados integrados en la Unión Europea a tenor de la expresa limitación que para ellos supone además dicha integración (sin perjuicio, asimismo, de que tal integración responda, en buena medida, a la búsqueda de un remedio con el que contener la globalización y de situarse mejor ante ella) ${ }^{21}$.

$\mathrm{La}$ anterior crisis constitucional ha generado diversas respuestas, como la búsqueda de nuevos espacios, en particular supra estatales, sobre los que articular nuevas Constituciones; pero ante la imposibilidad hoy de articular adecuadamente éstas, incluso a nivel regional-europeo, es que, al menos, se haya procedido a extender e impulsar instrumentos propiamente constitucionales a dichos espacios ordinamentales a fin de: no sólo parchear los agujeros que al interno de la normatividad constitucional ha generado la globalización, sino procurar resolver problemas globales que requieren respuestas a nivel constitucional ${ }^{22}$. Y es de este modo que el Derecho constitucional alcance en la actualidad cierta autonomía de las Constituciones normativas y del Estado, al extenderse a espacios tanto supraestatales (internacional y regional, especialmente en Europa), como infraestatales, a la par que, entonces, el Derecho constitucional total (en el entendido del efectivo Derecho constitucional que regula una determinada colectividad, más o menos

${ }^{18}$ Cfr. SÁnchez Barrilao, J.F., «Globalizzazione, tecnología e Costituzione: verso una Democracia planetaria e un Diritto costituzionale comune?», BuRATTI, A. (trad.), Nomos - Le attualità nel diritto 3 (2002): 169 y ss.

19 P.e., Jáuregui Bereciartu, G., «Del Estado nacional a la democracia cosmopolita (Política y Derecho en la era global», Anales de la Cátedra Francisco Suárez 36 (2002): 127-150.

${ }^{20}$ Cfr. CAssese, S., La crisi dello Stato (Editori Laterza, Roma-Bari, 2002).

${ }^{21}$ Nuevamente SÁNCHEZ BARRILAO, J.F., pero ahora «La constitucionalización de la integración regional europea: ¡más Europa! de vuelta a una Constitución para Europa, ante la situación de crisis de la Unión», Estudios de Deusto Vol. 60/2 (2012), 71 y ss.

${ }^{22}$ P.e. de Julios-Campuzano, A., La transición paradigmática de la teoría jurídica (El Derecho ante la globalización) (Madrid: Dykinson, 2009), Cap. V. 
amplia) pase a conformarse finalmente de manera compuesta en cuanto que resultante de diversos ordenamientos interrelacionados ${ }^{23}$.

Naturalmente el carácter compuesto hoy del Derecho constitucional conlleva, asimismo, una mayor complejidad del mismo, hasta el punto de que no pocos recursos se destinen más sobre cómo articular adecuadamente las relaciones de unos y otros concretos Derechos constitucionales ${ }^{24}$, que sobre los propios contenidos sustantivos. Y de esta forma que: de un lado, y a su vez, la condición conflictiva y compleja del Derecho constitucional total desemboque en un mayor protagonismo de los tribunales frente a los poderes políticos, que pierden presencia ${ }^{25}$; y de otro lado, que tanto lo anterior, como el carácter económico de la globalización (especialmente tras la crisis económica), vienen de tiempo socavando los postulados sustantivos propios del neoconstitucionalismo (a saber, democracia pluralista, reconocimiento y garantía de derechos y libertades, y políticas sociales) ${ }^{26}$, a la par que, incluso, se llega a instrumentar institutos constitucionales para fines contrarios a tales postulados ${ }^{27}$.

Es por tanto que, finalmente, se muestre el Derecho constitucional como un Derecho que se extiende más allá de la propia Constitución y del Estado, proyectando así contenidos e instituciones característicamente constitucionales a nuevos espacios y relaciones, pero, y sin embargo, normativamente más dúctil, abierto y dinámico en su realización ${ }^{28}$; un Derecho, además, culturalmente proyectado y compartido, a partir de aproximaciones comparadas de unos y otros sistemas constitucionales (Peter Häberle) ${ }^{29}$, mas con menor

${ }^{23}$ Cfr. Balaguer Callejón, F., «Fuentes del Derecho, espacios constitucionales y ordenamientos jurídicos», Revista Española de Derecho Constitucional 69 (2003): 181213.

${ }^{24}$ Así, vid. SÁnchez BARRILAO, J.F., «Constitución y relaciones entre ordenamientos en el contexto de la globalización», Estudios Constitucionales 12/2 (2014), 55-108.

${ }^{25}$ Otra vez CASSESE, S., pero ahora Il diritto globale (Giustizia e democracia oltre lo Stato) (Torino: Einaudi Editore, 2009).

26 Vid., desde una perspectiva nada sospechosa, HABERMAs, J., «La constelación posnacional», en La constelación posnacional (Ensayos políticos), PÉREz DíAz, L. (trad.) (Barcelona: Paidós, 2000): 81 y ss.

${ }^{27}$ Como aconteciera con la reforma del art. 135 CE de 2011, al introducirse una garantía del pago de la deuda pública (a modo de auténtico derecho constitucional), mientras que la efectiva garantía de los derechos sociales resulta silenciada; al respecto de esta reforma constitucional, y de la crisis constitucional que supone, vid. SÁNCHEZ BARRILAO, J.F., «La crisis de la deuda soberana y la reforma del artículo 135 de la Constitución Española», Boletín Mexicano de Derecho Comparado 137 (2013): 679-712.

${ }^{28}$ Por todos (cómo no), sobre una configuración más flexible de las normas constitucionales ya, cfr. Zagrebelsky, G., Diritto mite: Legge, diritti, giustizia, Einaudi, Torino, 1992.

${ }^{29}$ Häberle, P., Teoría de la constitución como ciencia de la cultura, Mikunda, E. (trad.), Tecnos, Madrid, 2000. 
grado de resistencia normativa al impulso fáctico que genera la globalización económica y tecnológica.

\section{SOBRE LA CONTINGENCIA Y LA INCERTIDUMBRE EN EL DERECHO}

Al hilo de la referida globalización tecnológica, ya que la tecnología hoy se presenta y desarrolla al amparo de la globalización (tanto por motivos económicos, como por la propia dinámica extensiva y comunicativa de la tecnología en la actualidad), es que el progreso tecnológico, y en especial a la luz del avance de la informática, se retroalimente y autoimpulse ganando también mayor velocidad; una velocidad, así, imagen de una tecnología motorizada y al respecto de una sociedad entonces en constante cambio y evolución. Claro que el cambio y la evolución es condición de la misma historia; pero lo característico hoy es, entonces, la velocidad e intensidad de tales cambios; y unos cambios propiciados, en gran medida (según se acaba de indicar), por una tecnología asimismo acelerada ${ }^{30}$. Ello repercute a su vez, trágicamente, en un Derecho cada vez más contingente, puesto que en constante mudanza a los nuevos tiempos ${ }^{31}$; y con esto, la dificultad del Derecho para ofrecer la necesaria seguridad jurídica que exige la libertad y el tráfico jurídico: lo más, de cierta previsibilidad que quepa hablarse ${ }^{32}$. Si tal contingencia es un problema actualmente para el Derecho (a pesar de los mecanismos que ya se habilitan a fin de mejorar el pulso entre el Derecho y la cambiante realidad que éste tiende a regular) ${ }^{33}$, mayor problema es con relación al Derecho constitucional, dado el superior grado de permanencia y estabilidad autopretendida por éste, puesto que dirigido a regular relaciones esenciales en la conformación política y jurídica de las comunidades.

Con lo anterior no es que postulemos volver a mejores tiempos de estabilidad jurídica, pues los tiempos están cambiando y ya son otros (mucho más veloces), sino advertir la necesidad de procurar nuevas formas y procedimientos normativos capaces de permitir cambios jurídicos más rápidos, mas con suficientes garantías a su vez de estabilidad (al menos en sus elementos

${ }^{30}$ Llegándose a hablar de un «tiempo fuera de sus goznes»; Ost, F., El tiempo del Derecho, Benítez Toriello, M.G. (trad.) (México: Siglo XXI, 2005), 264-278.

${ }_{31}$ Cfr. Sánchez Barrilao, J.F., De la ley al reglamento delegado (Deslegalización, acto delegado y transformaciones del sistema de fuentes), cit., Cap. 3.

32 Sobre la «previsibilidad» como referente gradual, relativo y alternativo de la certeza jurídica en la actualidad, vid. Gometz, G., La certeza jurídica como previsibilidad, Moreno Cruz, D. y Dei Vecchi, D. (trad.) (Madrid: Marcial Pons, 2012).

${ }_{33}$ Cfr., p.e., Sánchez Barrilao, J.F., De la ley al reglamento delegado... cit., Caps. IV, V y VI. 
esenciales) y de respeto del pluralismo y las minorías ${ }^{34}$; nuevas formas así para mantener la tensión entre una cierta estabilidad normativa, aunque dinámica, y una realidad en constante evolución.

A lo anterior, a su vez, se suma la incertidumbre con la que el Derecho es llamado a decidir sobre cuestiones tecnológicas, en general, e informáticas, en particular. Y ello, además, con la desventaja de cómo la tradicional limitación del Derecho ante lo científico y tecnológico (al decidir sobre cuestiones de esta naturaleza) daba lugar a la progresiva incorporación de criterios y sujetos propios de este ámbito, para al tiempo, y sin embargo, comprobarse cómo éstos perdían absolutidad a favor de lo porcentual mientras el Derecho continúa en su categórica obligación de responder de manera absoluta; y así, que la ciencia y lo tecnológico hayan ganado un espacio decisional al interno del Derecho, para luego, y sin embargo, relativizar su responsabilidad ante lo político y lo jurídico ${ }^{35}$. Por supuesto que la incerteza ha existido siempre en relación con la necesidad de decidir y resolver jurídicamente, y por tanto que el Derecho haya tenido que contar, entonces, con instrumentos para sortear aquélla (como es el caso de las presunciones); pero lo relevante hoy es, no obstante, la abrumadora incertidumbre en la que nos movemos precisamente a causa de una ciencia y tecnología que, al hilo de desvelar y articular verdades objetivas, acaban, sin embargo, por generar mayores incertezas en nuestro futuro, a la par que huye de dar respuestas absolutas cuando se le requiere. De este modo es que, finalmente, el Derecho haya tenido que buscar nuevos instrumentos, como son los principios de precaución (p.e. José Esteve Pardo) ${ }^{36}$ y de responsabilidad (cómo no, Hans Jonas) ${ }^{37}$.

En cuanto al primero, este principio se ha venido conjugando hasta ahora, fundamentalmente, en materias relativas al medio ambiente, la salud y la propia persona humana, además de recibir no pocas críticas, en particular por su naturaleza limitadora del progreso al justificar y articular limitaciones (o suspensiones) a actividades o productos sobre los que recaen sospechas

${ }^{34}$ Otra vez SÁnchez Barrilao, J.F., De la ley al reglamento delegado... cit., pp. 244 y ss.

${ }^{35}$ Cómo no, Esteve Pardo, J., «Decidir y regular en la incertidumbre. Respuestas y estrategias del Derecho Público», en AA.VV. Estrategias del Derecho ante la incertidumbre y la globalización (Madrid: Marcial Pons, 2015), 33 y ss.

${ }_{36}$ Nuevamente Esteve PARdo, J., pero ahora: «Principio de precaución. El Derecho ante la incerteza científica», Revista Jurídica de Catalunya Vol. 102/3 (2003), 689 y ss.; y «Ciencia y Derecho: La nueva división de poderes», junto a TEJadA PALACIOS, J. en Ciencia y Derecho: La nueva división de poderes (Madrid: Fundación Coloquio Jurídico Europeo, 2013), 123 y ss.

37 Jonas, H., El principio de responsabilidad (Ensayo de una ética para la civiliza-

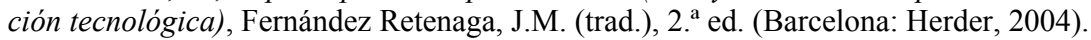


fundadas de producir un daño futuro ${ }^{38}$; no obstante, entendemos, siempre cabría la instrumentación de tal principio para casos de identificación de riesgos muy graves y potencialmente efectivos, y en especial al respecto de las personas (o de bienes de la máxima relevancia constitucional) ${ }^{39}$. En cuanto al principio de responsabilidad, más positivo en su desarrollo y más abierto al respecto de las materias en las que intervenir, parecería (entendemos) mejor llamado en atención a la propia naturaleza de los riesgos de la informática, al servir de guía positiva y neokantiana al propugnar un obrar compatible con el mantenimiento de la vida humana en relación con la actividad investigadora y a su ulterior realización o explotación; y de esta manera, procurando re-dirigir, más que prohibir, el desarrollo informático.

\section{LA INFORMÁTICA COMO OBJETO ESPECÍFICO DEL DERECHO CONSTITUCIONAL: DE LA MERA PROTECCIÓN DE DATOS A LA LIBERTAD INFORMÁTICA}

Sin duda alguna, la protección de datos no sólo es el espacio sustantivo constitucionalmente más desarrollado al respecto de la informática, sino también el primero al que las mismas Constituciones se refirieron, en atención al riesgo que para la intimidad de las personas se preveía ya que supondría tanto la acumulación de datos sobre aquéllas, como el cruce de los mismos y la creación de perfiles [así, y siguiendo a la portuguesa de 1976 (art. 35), art. $18.4 \mathrm{CE}]^{40}$; y a la sombra de ello, la búsqueda de respuestas, mecanismos e instrumentos en garantía de la persona frente a poderes públicos y privados (puesto que tal captación, acumulación, cruce y uso de datos no quedan reducidos a los poderes públicos hoy; al contrario, sujetos privados bien pueden poseer mayor capacidad informática que los primeros $)^{41}$, los cuales podemos articularlos en torno a tres grandes ejes.

${ }^{38}$ Sunstern, C.R., Leyes de miedo (Más allá del principio de precaución), Weinstabl, V.I. y De Hagen, S.M. (trad.) (Madrid: Katz Editores, 2009).

${ }_{39} \mathrm{Y}$ así, p.e., en relación al desarrollo de videojuegos en realidad virtual, en particular los de terror, y los riesgos que éstos pueden en ciertas personas frágiles; $c f r$. $<$ http://www. meristation.com/pc/noticias/estamos-muy-cerca-de-ver-la-primera-muerte-por-culpa-dela-realidad-virtual/58/2003320> (11/05/2016). No obstante, el principio de precaución se mueve más en un tiempo cautelar, una vez que ya se ha puesto a disposición del público un producto inicialmente conforme a la norma y al estado de la ciencia.

${ }^{40}$ Serrano Alberca, J.M., «Artículo 18.4», en AA.VV. Comentarios a la Constitución, Garrido Falla, F. (dir.), 2. ${ }^{a}$ ed. (Madrid: Civitas, 1985), 377-381.

${ }^{41}$ Ya en la década de los ochenta del pasado siglo, advirtiendo del riesgo para la intimidad al respecto, $c f r$. CAPPELLETTI, M., «¿Renegar de Montesquieu? La expansión y la legitimidad de la «justicia constitucional», De Luis Durán, P. (trad.), Revista Española de Derecho Constitucional 17 (1986), 12. 
Como primer eje cabe destacar la búsqueda de nuevas formas de decidir en relación a cuestiones técnicas, como la informática, a la par que especialmente delicadas tanto para los derechos y las libertades, como para el propio sistema económico y empresarial; y con ello, especialmente, la propuesta de una despolitización e independencia de los sujetos y criterios decisores, especialmente mediante agencias independientes y de índole técnico al respecto de su composición y parámetros de deci$\operatorname{sión}^{42}$. En tal sentido, precisamente, la Agencia de Protección de Datos, a nivel nacional (Tít. VI LO 15/1999, de 13 de diciembre, Protección de Datos de Carácter Personal) ${ }^{43}$, y sus homónimas europea (Comité Europeo de Protección de Datos) ${ }^{44}$ y autonómicas (al tiempo) ${ }^{45}$, supone la institucionalización de lo tecnológico en cuanto a las tomas de decisiones (normativas y administrativas) y la garantía primaria de los derechos (en especial, de la intimidad) de las personas ante acciones informáticas de sujetos públicos y privados.

En cuanto al segundo de los ejes, y desde una dinámica clásica del Derecho limitando determinadas acciones que dañan o ponen en riesgo derechos y bienes de la mayor relevancia jurídica (expresamente así el art. 18.4 CE) ${ }^{46}$, está toda una batería de prohibiciones sobre dichos sujetos (públicos y privados) y en relación con la captación, acumulación, manipulación, cesión y uso de datos relativos a las personas, y particularmente concernientes a la

${ }^{42}$ Sobre éstas, vid. BETANCOR RodríGUEZ, A., Las Administraciones independientes: un reto para el Estado social y democrático de Derecho (Madrid: Tecnos, 1994); también, Magide Herrero, M., Limites constitucionales de las administraciones independientes (Madrid: Instituto Nacional de Administración Pública, 2000).

${ }^{43}$ Cfr. Vizcaíno Calderón, M., «Naturaleza y régimen jurídico de la Agencia de Protección de Datos: Título VI. Agencia de Protección de Datos (Artículo 35)», en AA.VV. Comentario a la Ley Orgánica de Protección de Datos de Carácter Personal (Madrid: Civitas / Thomson Reuters, 2010), 1835-1859.

${ }^{44}$ Arts. 8.3 Carta de Derechos Fundamentales de la Unión Europea, 16.2 Tratado de Funcionamiento de la Unión Europea, 39 Tratado de la Unión Europea, y 68 y ss. Reglamento (UE) 2016/679 del Parlamento Europeo y del Consejo de 27 de abril de 2016 relativo a la protección de las personas físicas en lo que respecta al tratamiento de datos personales y a la libre circulación de estos datos y por el que se deroga la Directiva 95/46/CE (Reglamento general de protección de datos).

${ }_{45}$ Así, art. 41 LO 15/1999, y el 31, p.e., LO 6/2006, de 19 de julio, de reforma del Estatuto de Autonomía de Cataluña. Sobre dichas agencias a nivel autonómico, vid. AA.VV. Estudios sobre comunidades autónomas y protección de datos personales (II Encuentro entre Agencias Autonómicas de Protección de Datos Personales) (Madrid: Agencia de Protección de Datos de la Comunidad de Madrid, 2006).

${ }^{46}$ Desde esta perspectiva, vid. CASTElls ARTECHe, J.M., «La limitación informática», en AA.VV. Estudios sobre la Constitución Española. Homenaje al Profesor Eduardo García de Enterría (II) (Madrid: Civitas, 1991), 907 y ss. 
intimidad de éstas (en especial, art. 44 LO 15/1999); y en garantía de ello (y desde una dimensión represiva), importantes sanciones al respecto (arts. $45 \mathrm{y}$ 46 LO 15/1999), a la par que sencillos mecanismos de denuncia de tales conductas (p.e. arts. 13, 16 y 18 LO 15/1999).

Y como tercer y último eje está la reconocida capacidad de las personas para que decidan sobre sus datos, en particular mediante el consentimiento informado en relación con la captación y conservación de aquéllos, como al respecto de su posible uso, cesiones y retirada (arts. 5 y 6 LO 15/1999) ${ }^{47}$. Y es que, al margen de garantizarse con esto la titularidad misma y el ejercicio del derecho a la intimidad y a la libertad, se consigue asimismo compatibilizar el uso público y comercial de datos personales, esenciales tanto en un ámbito como en otro (arts. 11 y 12 LO 15/1999); sin duda, desde dicha perspectiva, el muy reciente Reglamento (UE) 2016/679 del Parlamento Europeo y del Consejo de 27 de abril de 2016, relativo a la protección de las personas físicas en lo que respecta al tratamiento de datos personales y a la libre circulación de estos datos ${ }^{48}$.

Al tiempo también han aparecido nuevos objetos para el Derecho constitucional en relación con la informática y los datos personales, como es el derecho al olvido ${ }^{49}$, en cuanto que capacidad jurídicamente reconocida a las personas para que se borren de las redes datos de éstas inicialmente de trascendencia pública, pero que bien pueden, a los años, limitar y constreñir la libertad de aquéllas. El desarrollo tecnológico-informático permite, en especial mediante potentes motores de búsqueda en internet, recopilar en instantes múltiples datos pasados que, siendo originariamente de interés público, al

47 Vid. Messía de la Cerda Ballesteros, F.J., «El consentimiento y el derecho a la Protección de Datos de Carácter Personal», Nuevas Politicas Públicas: Anuario Multidisciplinar para la Modernización de las Administraciones Públicas 1 (2005): 267 y ss.

${ }^{48}$ Considerando 13: «Para garantizar un nivel coherente de protección de las personas físicas en toda la Unión y evitar divergencias que dificulten la libre circulación de datos personales dentro del mercado interior, es necesario un reglamento que proporcione seguridad jurídica y transparencia a los operadores económicos, incluidas las microempresas y las pequeñas y medianas empresas, y ofrezca a las personas físicas de todos los Estados miembros el mismo nivel de derechos y obligaciones exigibles y de responsabilidades para los responsables y encargados del tratamiento, con el fin de garantizar una supervisión coherente del tratamiento de datos personales y sanciones equivalentes en todos los Estados miembros, así como la cooperación efectiva entre las autoridades de control de los diferentes Estados miembros. El buen funcionamiento del mercado interior exige que la libre circulación de los datos personales en la Unión no sea restringida ni prohibida por motivos relacionados con la protección de las personas físicas en lo que respecta al tratamiento de datos personales».

49 P.e., Rallo Lombarte, A., El derecho al olvido en internet: Google versus España (Madrid: CEPC, 2014). 
tiempo deberían, de manera ordinaria, haberse olvidado, permitiendo de esta forma a las personas segundas oportunidades en sus vidas ${ }^{50}$.

De alguna forma, finalmente ( $\mathrm{y}$ al hilo de todo lo anterior), es que quepa hablarse constitucionalmente de cierta «libertad informática» (ya, V. Frosini $)^{51}$, en tanto que capacidad reconocida a las personas en relación a su autodeterminación informativa o ante la informática ${ }^{52}$ : «derecho a controlar el uso de los mismos datos insertos en un programa informático» [STC 254/1993, de 20 de julio (FJ 7)] $]^{53}$. Y al tiempo, incluso, la expresa positivización normativa de dicho derecho más allá de la mera protección de la intimidad frente a los datos personales (todavía, art. 18.4 CE), como ya acontece en Europa en su nivel superior del sistema de fuentes con ocasión del artículo 8.1 y 2 de la Carta de Derechos Fundamentales de la Unión Europea $^{54}$.

50 Vid. Simón Castellano, P., El régimen constitucional del derecho al olvido digital (Valencia: Tirant Lo Blanc, 2012); también, HeRnández Ramos, M., Derecho al olvido en internet como nuevo derecho fundamental en la sociedad de la información. Perspectiva constitucional española y europea, Quid Iuris Vol. 21 (2013): 115 y ss. Al tiempo, y positivizado ya expresamente en Europa, nuevamente Reglamento (UE) 2016/679 del Parlamento Europeo y del Consejo, art. 17.

${ }^{51}$ Frosini, V., «Bancos de datos y tutela de la persona», Revista de Estudios Políticos 30 (1982), 21-40.

52 Cfr. LuCAs Murillo de la Cueva, P., El derecho a la autodeterminación informativa: la protección de los datos personales frente al uso de la informática (Madrid: Tecnos, 1991). También, y especialmente, vid. SÁnchez Bravo, A.A.: La protección del derecho a la libertad informática en la Unión Europea (Sevilla: Universidad de Sevilla, 1998), 57 y ss.; o más recientemente, «Los datos personales en las sociedades tecnológicas: de la intimidad a la libertad informática», en AA.VV. Multiculturalismo, tecnología y medioambiente (Sevilla: Punto Rojo, 2015), 155-191.

53 Sobre ésta, ORTí VALLEJo, A.P., «El nuevo derecho fundamental (y de la personalidad) a la libertad informática (A propósito de la STC 254/1993, de 20 de julio)», Derecho privado y Constitución 2 (1994): 305-332.

${ }^{54}$ El básico art. 8.1 CDFUE: «Toda persona tiene derecho a la protección de los datos de carácter personal que le conciernan». Y el más desarrollado art. 8.2 CDFUE: «Estos datos se tratarán de modo leal, para fines concretos y sobre la base del consentimiento de la persona afectada o en virtud de otro fundamento legítimo previsto por la ley. Toda persona tiene derecho a acceder a los datos recogidos que le conciernan y a obtener su rectificación». Al respecto, vid. ÁviLA RodríGuez, C.M., «Artículo 8. Protección de datos de carácter personal», en AA.VV. La Europa de los derechos (Estudio sistemático de la carta de los derechos fundamentales de la Unión Europea) (Granada: Comares, 2012). Con todo, se ha de advertir el riesgo que para este derecho supone la tendencia funcional del Tribunal de Justicia en relación al proceso de integración; de interés, vid. RoDRÍGUEZIZQuiERdo SERrano, M., «El Tribunal de Justicia y los derechos en la sociedad de la información: privacidad y protección de datos frente a las libertades informativas», Revista de Derecho Constitucional Europeo 24 (2015). 


\section{LA INFORMÁTICA COMO TRANSFORMACIÓN DE LO CONSTITUCIONAL}

El referido desarrollo informático nos muestra también cómo objetos constitucionales se ven, sin embargo, transformados al hilo del cambio de la realidad (relativa al supuesto de hecho de la norma) por efecto de la evolución tecnológica. Tal vez el ejemplo más importante (y ya también clásico) sea el progreso vivido en torno a los modos de comunicación personal, pasando de la postal y la telefonía (art. $18.3 \mathrm{CE})^{55}$, al email o correo electrónico, así como a otros sistemas de mensajería electrónica; y ello no sólo en relación con los cambios físicos de tales tipos de comunicación y de sus medios (terminales y redes), sino a la conservación de los datos objeto de la comunicación y las nuevas formas de captación de éstos y de ella misma ${ }^{56}$.

En tal sentido, además, están los propios cambios que ha sufrido la telefonía en cuanto que, de un lado, hoy digital ${ }^{57}, \mathrm{y}$, de otro, integrada en soportes que exceden en mucho la mera comunicación telefónica: los smartphones, y en tanto que auténticos ordenadores portátiles en miniatura. Y al hilo de estos otros cambios la fusión de tecnologías diversas, como es el caso de las smartv, y antes, y simplemente, la televisión visionada en ordenadores a partir de meras placas sintonizadoras (como en relación a canales televisivos en internet); precisamente sobre esto último, destaca la cuestión constitucional surgida en Italia a comienzos de la década pasada al respecto de si debía pagarse allí el canon televisivo no sólo en razón al número de receptores de televisión existentes, sino en relación asimismo a los ordenadores y sus monitores (Sentencia 284/2002, de 26 de junio, de la Corte costituzionale italiana).

También, como manifestación de transformaciones de derechos constitucionales a tenor de la informática, está la evolución que han supuesto las redes sociales e internet al respecto de la libertad de expresión e información, de manera que libertades clásicas se han visto afectas, por no decir que mutadas; así por ejemplo, y en relación con internet, se advierte no sólo la proliferación de periódicos on line (tanto de tirada paralela en papel, como exclusivamente digitales), sino de blogs o meras páginas webs en las que los ciudadanos expresan

55 P.e., y originariamente, Martín Morales, R., El régimen constitucional del secreto de las comunicaciones (Madrid: Civitas, 1995).

56 Vid.: Rodríguez RuIz, B., El secreto de las comunicaciones: tecnología e intimidad (Madrid: McGraw-Hill Interamericana de España, 1998); FERNÁNDEZ RodríGUEz, J.J., Secreto e Intervención de las Comunicaciones en Internet (Pamplona: Aranzadi, 2004); o Rodríguez LAINZ, J.L., «Internet de los objetos y secreto de las comunicaciones», Diario La Ley 8034 (2013).

${ }^{57}$ En concreto, sobre la interceptación digital de las comunicaciones telefónicas, vid. nuevamente RoDRíGUEZ LAINZ, J.L., pero ahora «SITEL: nuevas tendencias, nuevos retos», Diario La Ley 8082 (2013). 
opiniones y presentan informaciones, a la par que pueden acceder libremente a ellas (en tal sentido, resulta básica la Sentencia del Tribunal Supremo norteamericano 26 de junio de 1997, en el caso Communications Decency Act $)^{58}$.

Ya en España (nuevamente), otro ejemplo de cómo la informática e internet han cambiado la realidad sobre la que venía actuando el Derecho constitucional ha sido la aparición del juego on line (L 13/2011, de 27 de mayo, de regulación del juego), y las transformaciones que ello ha supuesto al respecto del reparto competencial ahora entre el Estado y las Comunidades Autónomas en relación al juego y su fiscalidad (p.e., originariamente, las Sentencias del Tribunal Constitucional 163 y 164/1994, de 26 de mayo) ${ }^{59}$, además de su proyección desde el ámbito supranacional; y así que, más allá de la delimitación territorial de la actividad (como criterio competencial fundamental), que se plantee luego la eficacia real de la normativa competente al respecto de prestadores foráneos (de fuera del territorio), como la propia dificultad tecnológica para que coincida el ámbito del juego con la estrictamente competencial ${ }^{60}$.

\section{LA INFORMÁTICA COMO CAUSA DE CONFLICTOS CONSTITUCIONALES}

Con todo, se ha de admitir que donde la informática sigue en mayor contacto con el Derecho constitucional es con ocasión de la aparición de conflictos entre aquélla y otros ámbitos reconocidos y garantizados constitucionalmente, como así acontece en relación con la intimidad o las comunicaciones (según se acaba de señalar), pero no solamente. De este modo, una cuestión todavía abierta a nivel europeo, y al respecto de la protección de la dignidad de la persona (en particular, a partir del caso

${ }^{58}$ Sobre ella, Frosini, T.E., «Nuevas tecnologías y constitucionalismo», GómEZ Lugo, Y. (trad.), Revista de Estudios Políticos 124 (2004), especialmente 138-143. También de interés, sobre las transformaciones de las libertades de expresión e información con ocasión de las redes e internet, vid. SÁNCHEz FERRIZ, R., «Conceptos clásicos de libertades informativas: redefinición e incidencia de las TICs», en AA.VV. Libertades de expresión e información en internet y las redes sociales: ejercicio, amenazas y garantías (Valencia: Servei de Publicacions de la Universitat de València, 2011), 36-43.

59 Vid. Serrano Lozano, R., «Juegos, apuestas y casinos», en AA.VV. Reformas estatutarias y distribución de competencias (Sevilla: Instituto Andaluz de Administración Pública, 2007), 843 y ss.; también, NARANJO DE LA CRUZ, R., «Artículo 43. Alcance territorial y efectos de las competencias», en AA.VV. Comentarios al Estatuto de Autonomía para Andalucía (II) (Sevilla: Parlamento de Andalucía, 2012): 713 y 714.

${ }^{60}$ Cfr. Gamero CASAdo, E., «Artículo 81. Juego», en AA.VV. Comentarios al Estatuto de Autonomía para Andalucía (II)... cit., 1343-1347. También, vid. Sentencia del Tribunal Constitucional 35/2012, de 15 de marzo. 
Omega $)^{61}$, es la referida a la censura y prohibiciones de ciertos videojuegos (o contenidos de los mismos) ante roles violentos y actitudes máximo sexistas (más allá de la mera limitación de acceso a ellos según la edad) ${ }^{62}$. O también recientemente, y en Estados Unidos, el requerimiento del F.B.I. a los de Cupertino del código del iPhone a fin de desbloquear el terminal del asaltante de San Bernardino (de diciembre de 2015), mientras que éstos, accediendo siempre a colaborar con sus propios ingenieros, se negaban sin embargo a tal entrega aduciendo su obligación (en cuanto que compromiso) de proteger la seguridad e intimidad de sus clientes; con todo, y finalmente, el F.B.I. consiguió desbloquear dicho aparato (ya, a finales de marzo de 2016) ${ }^{63}$.

Pero también el propio progreso constitucional termina por incidir con la informática y otros contenidos constitucionales en la búsqueda de un mejor gobierno ${ }^{64}$, como así sucede con ocasión del reciente reconocimiento del principio de transparencia de la actuación de los poderes públicos y de sus titulares, de un lado, y la puesta a disposición informática de la ciudadanía de múltiples datos de éstos (Portal de la Transparencia) a fin del consiguiente y efectivo control político de aquéllos (art. 105.b CE y L 19/2013, de 9 de diciembre, de transparencia, acceso a la información pública y buen gobierno) ${ }^{65}$; y por otra parte, y sin embargo, la necesaria guardia de la intimidad de tales sujetos frente

${ }^{61}$ Sentencia del Tribunal de Justicia de la Comunidad Europea (Sala 1. ${ }^{a}$ ) de 14 de octubre de 2004 (AS. C-36/02); y al respecto de ésta, vid. SÁnchez LorEnZo, S.A., «Derechos fundamentales y libertades de circulación a la sombra de una Constitución para Europa: Comentario a la Sentencia TJCE (Sala 1.a), de 14 de octubre de 2004 (Asunto C-36/02: «Omega»)», Revista de Derecho Constitucional Europeo 5 (2006), 383-391.

${ }_{62}$ P.e., <http://www.malavida.com/listas/videojuegos-censurados-005925> (11/05/2016). También: Comunicación de la Comisión al Parlamento Europeo, al Consejo, al Comité Económico y Social y al Comité de las Regiones, de 22 de abril de 2008, sobre la protección de los consumidores, en especial de los menores, en lo que respecta al uso de los videojuegos [COM(2008) 207 final]; e Informe de la Comisión al Parlamento Europeo, al Consejo, al Comité Económico y Social Europeo y al Comité de las Regiones de 13 de septiembre de 2011 sobre la aplicación de la Recomendación del Consejo, de 24 de septiembre de 1998, relativa a la protección de los menores y de la dignidad humana y de la Recomendación del Parlamento Europeo y del Consejo de 20 de diciembre de 2006 relativa a la protección de los menores y de la dignidad humana y al derecho de réplica en relación con la competitividad de la industria europea de servicios audiovisuales y de información en línea denominada «La protección de los menores en el mundo digital» [COM(2011) 556 final].

${ }_{63}$ Rodríguez LaINZ, J.L., «¿Podría un juez español obligar a Apple a facilitar una puerta trasera para poder analizar información almacenada en un iPhone 6?», Diario La Ley 8729 (2016).

${ }^{64}$ Vid. Bergareche, B., «Umbrales de transparencia en la era WikiLeaks», Política Exterior Vol. 26/148 (2012): 162-171.

${ }^{65}$ Entre otros, vid. Cotino Hueso, L., «La nueva Ley de transparencia y acceso a la información», Anuario de la Facultad de Derecho 7 (2014), 241-256. 
a los ciudadanos, de manera que ciertos datos personales no se hagan públicos (art. 15 L 19/2013, y el propio 105.b, in fine, CE) ${ }^{66}$.

Además, entroncando con recientes desarrollos del principio democrático, $\mathrm{y}$ a tenor del peso de internet y de las redes sociales al respecto de nuevas formas de participación de la ciudadanía en el espacio público ${ }^{67}$, un conflicto ya clásico entre la sociedad civil y los poderes públicos en cuanto al internet viene siendo el planteado a partir del siguiente trinomio: de una parte los usuarios de internet, reclamando un especio independiente y virtual frente a los poderes públicos, y demandando de esta forma, y desde cierta subsidiariedad horizontal, el autogobierno y la autorregulación de internet ${ }^{68}$; de otra los poderes públicos, invocando un interés general sobre internet en tanto que red de comunicación no sólo social, sino económica y política, de manera que aquéllos no pueden quedar al margen del gobierno y la regulación de internet ${ }^{69} ; \mathrm{y}$ desde una dimensión intermedia (en la que confluyen diversos intereses y realidades) ${ }^{70}$, la garantía de una efectiva neutralidad política de éste y de las redes dada su cualificada consideración de autopista de comunicación y de zona de puesta en común hoy para la ciudadanía y a modo de nuevo espacio público virtual ${ }^{71}$, llegándose a hablar de auténtica agora moderna ${ }^{72}$.

${ }^{66}$ Moretón Toquero, M. A., «Los límites del derecho de acceso a la información pública», Revista Jurídica de Castilla y León 33 (2014).

${ }^{67}$ P.e. Candela Talavero, J.E., «Los medios de comunicación, la democracia representativa y el espacio público», Universitas: Revista de Filosofía, Derecho y Política 21 (2015), 96-111.

${ }_{68}$ Así, Galindo AyUdA, F., «Autorregulación y códigos de práctica en Internet...», Revista Aragonesa de Administración Pública Núm. Extra 4 (2001), 19-60.

${ }^{69}$ García Costa, F.M., «El gobierno de Internet como reto del Derecho Constitucional», Anales de Derecho 24 (2006), 267-292.

${ }^{70}$ Cfr. Rodríguez Puerto, M.J., «La regulación de Internet y la teoría jurídica», Anuario de Filosofía del Derecho 24 (2007), 441-464; asimismo, de interés, vid. RodRíGUEz GarcíA, L.F., «Políticas de la Federal Communications Commission en materia de neutralidad de la red», en AA.VV. Libertades de expresión e información en internet y las redes sociales... cit., 99-113.

71 Vid. Fuertes López, M., «En defensa de la neutralidad de la red», Revista Vasca de Administración Pública Núms. 99-100 (2014), 1397-1412; o LoPes MATsushiTA, T., «El derecho, la sociedad de la información y el principio de la neutralidad de red: consideraciones sobre el mercado y el acceso a la información», Revista de Derecho, Comunicaciones y Nuevas Tecnologías 11 (2014). Ya, a nivel europeo, Reglamento (UE) 2015/2120 del Parlamento Europeo y del Consejo, de 25 de noviembre de 2015, por el que se establecen medidas en relación con el acceso a una internet abierta y se modifica la Directiva 2002/22/CE relativa al servicio universal y los derechos de los usuarios en relación con las redes y los servicios de comunicaciones electrónicas y el Reglamento (UE) 531/2012 relativo a la itinerancia en las redes públicas de comunicaciones móviles en la Unión.

72 SÁnchez FERrIZ, R., «Conceptos clásicos de libertades informativas: redefinición e incidencia de las TICs... cit, en especial pp. 42-43. 


\section{DE VUELTA A LA INFORMÁTICA COMO OBJETO CONSTITUCIONAL: DE LA PREVISIÓN DE NUEVOS LÍMITES CONSTITUCIONALES EN RELACIÓN CON LA INFORMÁTICA, A LA PROMOCIÓN CONSTITUCIONAL DE LA INFORMÁTICA}

Los anteriores supuestos, y la necesaria resolución de los conflictos que a nivel constitucional origina (o a los que contribuye) la informática, acaba por desencadenar nuevas prohibiciones y limitaciones de concretas actuaciones informáticas en razón al daño originado o esperado (potencial) para bienes de la máxima relevancia constitucional; y en tal sentido, incluso, el impulso desde los poderes públicos de una función de custodia e investigación al respecto del uso de la informática y de internet y las redes por terceros que puedan poner en peligro la garantía de la seguridad del tráfico social, económico y político. En tal sentido, no ya la mera acción de los hackers, sino ciertas actos, como es la elaboración y puesta en circulación de malware para el espionaje de la actividad informática de sujetos, o la sustracción de datos, o simplemente la mera destrucción de sistemas y/o computadoras, es que resulten genérica y abstractamente prohibidos ${ }^{73}$, sin perjuicio de que singulares acciones puedan resultar justificadas por el sistema en tanto que al servicio de bienes de especial relevancia constitucional ${ }^{74}$. Y por otra parte, además, los riesgos de la conocida como Deep web, dado que más de $90 \%$ de todo internet y espacio de tráfico oculto a los buscadores y al margen, en gran medida, del control público ${ }^{75}$.

También, pero a la inversa, el planteamiento de limitaciones y prohibiciones de actuaciones informáticas (tanto a nivel de software, como de hardware) en cuanto que potencialmente (supuesta o manifiestamente) destinadas

${ }^{73}$ De interés, Arteaga Martín, F., «Ciberseguridad en España: ¿problema u oportunidad?», Politica Exterior Vol. 29/163 (2015): 148 y ss.

${ }^{74} \mathrm{Y}$ ello tanto en relación con los poderes públicos (p.e. los servicios de inteligencia nacionales y la defensa, sin perjuicio de las debidas garantías jurídicas en su acción, claro; $c f r$. ITALIANO, I., «La protezione dei dati personali nella giurisprudenza della Corte europea dei diritti umani», en AA.VV. Desafios para los derechos de la persona ante el siglo XXI: Internet y nuevas tecnologías (Pamplona: Thomson Reuters / Aranzadi, 2013), especialmente, 203-206), como, e incluso, de los propios particulares (según se ha puesto ya en evidencia con ocasión de la publicación masiva de datos de la máxima relevancia pública, como ha venido a suceder con relación a WikiLeaks, o más recientemente al respecto de los papeles de Panamá; p.e., vid. EcheVERri URUBuru, Á., «»Wikileaks» y los "Arcana Imperii»», en AA.VV. Libertad de expresión e información en Internet: amenazas y protección de los derechos personales (Madrid: CEPC, 2013), 325-338).

75 Vid. GONZÁlez SAN JUAN, J.L., «Internet profunda: wild wild west», en AA.VV. Reflexiones sobre derecho privado patrimonial Vol. 5 (Salamanca: Ratio Legis, 2015), 221-241. 
al servicio de conductas prohibidas por el ordenamiento, como precisamente se ha planteado al respecto de determinados programas que son utilizados para el pirateo informático, por más que en abstracto destinados a usos asimismo lícitos (p.e. programas P2P y el intercambio de ficheros), o de tarjetas de memoria que permiten, entre otros usos legales, el evidente pirateo ahora de consolas de juego (flashcard R4).

Sin embargo la informática no sólo supone nuevos problemas para el Derecho constitucional (según se acaba de mostrar), sino que asimismo conllevan posibilidades que se abren para el progreso democrático, económico, cultural y social; no en vano, la referida neutralidad de la red responde a cómo internet y las redes sociales han configurado un nuevo espacio público virtual que abre novedosas formas de participación y reivindicación ciudadana. De ahí, entonces, que desde el Derecho constitucional quepa promoverse, por ejemplo, la articulación informática de relaciones entre los poderes públicos y las personas (y los ciudadanos), la teleadministración o administración on line, de modo que éstas (y éstos) puedan entrar directamente en contacto con la Administración, y facilitando así las relaciones de unos y otros (sin perjuicio, eso sí, de las necesarias garantías al respecto) $)^{76}$; mas con ello, también, la necesidad de rediseñar, a tales efectos, cauces de comunicación y notificación lo suficientemente seguros como para garantizar la fehaciencia de las consiguientes actuaciones ante y de la Administración (así, y en España, las novedosas Leyes 39/2015, de 1 de octubre, del Procedimiento Administrativo Común de las Administraciones Públicas, y 40/2015, de 1 de octubre, de Régimen Jurídico del Sector Público -Tít. preliminar, Cap. V-, como la anterior 11/2007, de 22 de junio, de acceso electrónico de los ciudadanos a los Servicios Públicos) ${ }^{77}$. E incluso, diversas propuestas de teledemocracia (mediante voto electrónico), de manera que se facilite y agilice la participación democrática de los ciudadanos tanto en consultas populares, como en procesos electorales ${ }^{78}$.

${ }^{76}$ Cómo no, y tempranamente, Frosini, V., «Informática y Administración Pública», Revista de Administración Pública 105 (1984), 447-458. Más recientemente, Alòs MoNER, A., «E-gobierno: ¿modernización o fosilización de la administración?», El Profesional de la Información Vol. 20/3 (2011), 245 y ss.

77 P.e., vid.: GonzÁlez Bustos, M.A., «Servicios de información y gestión administrativa: la administración electrónica», en AA.VV. Fundamentos de Derecho Administrativo, 4. ${ }^{a}$ ed. (Salamanca: Ratio Legis, 2016), 239-264; o SÁnchez SÁnchez, Z., «Las nuevas leyes de régimen jurídico y procedimiento administrativo: afianzamiento de la administración electrónica en las relaciones internas de la Administración y con los ciudadanos», en AA.VV. Instituciones de procedimiento administrativo común: novedades de la Ley 39/2015 del Procedimiento Administrativo Común de las Administraciones (Curitiva: Juruá Eitora, 2016), 43-66.

78 AA.VV. El voto electrónico y sus dimensiones jurídicas (Entre la ingenua complacencia y el rechazo precipitado), BARRAT I EsteVE, J. (coord.), (Madrid: Iustel, 2016). 
Cuestión afecta, pero redimensionada, es cómo a través de la informática la Administración puede mejorar no sólo sus relaciones con las personas (y los ciudadanos), sino incluso facilitar el acceso de aquéllas que se encuentren en situaciones de mayor dificultad a la hora de entrar en contacto con sujetos públicos y/o privados (ya sea por razones personales, o del medio en el que se hallen...), de forma que la informática se convierte hoy en una herramienta esencial al respecto del Estado social y la prestación de servicios públicos (p.e. teleasistencia, o programas de enseñanza o formación on line).

Desde tal perspectiva, por tanto, es que el progreso y el desarrollo informático quepa verse además desde una particular y positiva dimensión por el Derecho constitucional, en atención con la contribución de la informática en objetos y bienes de la máxima relevancia constitucional (y más allá, así, del mero progreso que en abstracto supone aquélla al respecto del desarrollo económico, cultural y social), de manera que la informática alcance una particular extensión de fomento por y para los poderes públicos en sus diversas manifestaciones en relación con la ciudadanía (los referidos arts. -al inicio de estas páginas- 16.2 y 17.2 Constitución de la República de Ecuador, 63 Constitución de la República Dominicana, o 6 Constitución Mexicana) ${ }^{79}$. Una dimensión que, a su vez, justifica que algunos espacios propios de la informática, como sucede con el acceso a internet, se integren incluso en la moderna categoría del servicio universal ${ }^{80}$ : así, artículo 52 de la Ley 2/2011, de 4 de marzo, de Economía sostenible, relativo a la inclusión, como parte integrante del servicio universal, de una conexión que permitiera comunicaciones de datos de banda ancha a una velocidad de 1 Mbit por segundo ${ }^{81}$.

Desde tal dimensión positiva de la informática y de las redes ahora, es que destaquemos: de un lado, el progresivo reconocimiento normativo de ésta (al más alto nivel); y de otro, el desarrollo de políticas dirigidas a fomentar determinadas proyecciones de la informática, e integradas a la postre en amplias agendas públicas, como acontece tanto a nivel europeo, como nacional. En cuanto a lo primero, y al amparo de los muy genéricos artículos 179

${ }^{79} \mathrm{Y}$ ello, en conexión con los arts. 27.1, in fine, DUDH y 15.1.b PIDESC, los cuales vienen a reconocer un derecho humano a participar en el progreso tecnológico; al respecto de esto, vid. RODRÍGUEZ GUERRA, J., «Derecho al conocimiento y al progreso científico y a sus aplicaciones. El problema de la propiedad intelectual (art. 27.1 DUDH; art. 15 PIDESC)», en AA.VV. El sistema universal de los derechos humanos (Granada: Comares, 2014), 733-746.

${ }^{80}$ P.e. Davara Fernández de Marcos, M.Á., «La consideración de Internet como servicio universal de telecomunicaciones», en AA.VV. XVII Encuentros sobre Informática y Derecho, 2002-2003 (Pamplona: Universidad Pontificia de Comillas/Aranzadi, 2003), 289 y ss.

${ }_{81}$ Vid. Orza Linares, R., «Derechos fundamentales e internet: nuevos problemas, nuevos retos», Revista de Derecho Constitucional Europeo 18 (2012), 289 y ss. 
y 180 del Tratado de Funcionamiento de la Unión Europea ${ }^{82}$ y del más concreto marco establecido por La estrategia europea de crecimiento $2020^{83}$, es que ésta haya aprobado la Agenda digital (Estrategia i2010) para Europa ${ }^{84}$, previendo como acciones: la alfabetización mediática en el entorno digital ${ }^{85}$; el acceso de las regiones rurales a las $\mathrm{TIC}^{86}$; i2010 y las bibliotecas

${ }^{82}$ Respectivamente, art. 179 TFUE: «1. La Unión tendrá por objetivo fortalecer sus bases científicas y tecnológicas, mediante la realización de un espacio europeo de investigación en el que los investigadores, los conocimientos científicos y las tecnologías circulen libremente, y favorecer el desarrollo de su competitividad, incluida la de su industria, así como fomentar las acciones de investigación que se consideren necesarias en virtud de los demás capítulos de los Tratados. / 2. A tal fin, la Unión estimulará en todo su territorio a las empresas, incluidas las pequeñas y medianas, a los centros de investigación y a las universidades en sus esfuerzos de investigación y de desarrollo tecnológico de alta calidad; apoyará sus esfuerzos de cooperación con el fin, especialmente, de permitir que los investigadores cooperen libremente por encima de las fronteras y que las empresas aprovechen las posibilidades del mercado interior, en particular por medio de la apertura de la contratación pública nacional, la definición de normas comunes y la supresión de los obstáculos jurídicos y fiscales que se opongan a dicha cooperación. / 3. Todas las acciones de la Unión que se realicen en virtud de los Tratados, incluidas las acciones de demostración, en el ámbito de la investigación y del desarrollo tecnológico se decidirán y se ejecutarán de conformidad con lo dispuesto en el presente título». Y art. 180 TFUE: «Para la consecución de los mencionados objetivos, la Unión realizará las siguientes acciones, que, a su vez, completarán las acciones emprendidas en los Estados miembros: a) ejecución de programas de investigación, de desarrollo tecnológico y de demostración, promoviendo la cooperación con las empresas, los centros de investigación y las universidades, y de estas entidades entre sí; b) promoción de la cooperación en materia de investigación, de desarrollo tecnológico y de demostración de la Unión con los terceros países y las organizaciones internacionales; c) difusión y explotación de los resultados de las actividades en materia de investigación, de desarrollo tecnológico y de demostración de la Unión; d) estímulo a la formación y a la movilidad de los investigadores de la Unión». También, $c f r$. art. 3 TUE. Por otra parte, al respecto de las bases constitucionales del progreso informático en el seno de la Unión Europea (de manera crítica), vid. Sánchez Barrilao, J.F., «Los fundamentos del «progreso informático» en la Unión Europea» (en prensa).

${ }^{83} \mathrm{Vid}$. <http://www.lamoncloa.gob.es/espana/eh15/politicasocial/Documents/Europa-2020-la-estrategia-europea-de-crecimientoA.pdf> (24/04/2016).

${ }^{84} \mathrm{Cfr}$. http://eur-lex.europa.eu/summary/chapter/information_society.html?root default=SUM_1_CODED\%3D31,SUM_2_CODED\%3D3102\&obsolete=false\#arr ow_3102 (24/04 $/ \overline{2} 016)$.

${ }^{85}$ Recomendación 2009/625/CE de la Comisión, de 20 de agosto de 2009, sobre la alfabetización mediática en el entorno digital para una industria audiovisual y de contenidos más competitiva y una sociedad del conocimiento incluyente.

${ }^{86}$ Comunicación de la Comisión al Consejo y al Parlamento Europeo «Mejorar el acceso de las zonas rurales a las modernas tecnologías de la información y la comunicación (TIC)» [COM(2009) 103 final]. 
digitales ${ }^{87}$; iniciativas sobre integración numérica ${ }^{88}$; el «envejecimiento mejor» en la sociedad de la información (Plan de acción sobre tecnologías de la información y la comunicación y envejecimiento) $)^{89}$; el programa eContentplus (2005-2008) ${ }^{90}$; la administración electrónica eGovernment ${ }^{91}$; y la anterior iniciativa eEurope (Una sociedad de la información para todos) ${ }^{92}$. También, de interés, el diseño por la Comisión de una estrategia para crear un mercado único digital en Europa (en base a tres pilares: mejorando el acceso de los consumidores y las empresas a los bienes y servicios digitales en toda Europa; creando las condiciones adecuadas y garantizar la igualdad de condiciones para que las redes digitales y los servicios innovadores puedan prosperar; y maximizando el potencial de crecimiento de la economía digital $)^{93}$, y al hilo de ello el reciente planteamiento de la digitalización de la industria europea ${ }^{94}$ mediante: dicha digitalización de la industria, aprovechando todas las ventajas de un mercado único digital ${ }^{95}$; una Iniciativa Europea de Computación en Nube, y en relación a una economía competitiva de

${ }^{87}$ Comunicación de la Comisión de 30 de septiembre de 2005 al Parlamento Europeo, el Consejo, el Comité Económico y Social Europeo y al Comité de las Regiones -i2010: bibliotecas digitales [COM (2005) 465 final].

${ }^{88}$ Comunicación de la Comisión al Parlamento Europeo, al Consejo, al Comité Económico y Social Europeo y al Comité de las Regiones de 8 de noviembre de 2007 - «Iniciativas europeas i2010 sobre la inserción numérica- Participar en la sociedad de la información» [COM(2007) 694 final].

${ }^{89}$ Comunicación de la Comisión al Parlamento Europeo, al Consejo, al Comité Económico y Social Europeo y al Comité de las Regiones, de 14 de junio de 2007, «Envejecer mejor en la sociedad de la información -Una iniciativa i2010- Plan de acción sobre tecnologías de la información y la comunicación y envejecimiento» [COM (2007) 332 final].

${ }^{90}$ Decisión n. ${ }^{\circ} 456 / 2005 / \mathrm{CE}$ del Parlamento Europeo y del Consejo, de 9 de marzo 2005 , por la que se establece un programa plurianual comunitario de incremento de las posibilidades de acceso, utilización y explotación de los contenidos digitales en Europa.

${ }^{91}$ Comunicación de la Comisión, de 26 septiembre 2003, al Consejo, al Parlamento Europeo, al Comité Económico y Social Europeo y al Comité de las Regiones -El papel de la administración electrónica en el futuro de Europa [COM (2003) 567 final].

${ }_{92}$ Comunicación, de 8 de diciembre de 1999, relativa a una iniciativa de la Comisión para el Consejo Europeo extraordinario de Lisboa de 23 y 24 de marzo de 2000: eEurope -Una sociedad de la información para todos [COM (1999) 687].

${ }_{93}$ Comunicación, de 6 de mayo de 2015, de la Comisión al Parlamento Europeo, al Consejo, al Comité Económico y Social Europeo y al Comité de las Regiones [COM(2015) 192 final]. -Una estrategia para el mercado único digital europeo.

$94<$ http://europa.eu/rapid/press-release_IP-16-1407_es.htm> (25/04/2016).

${ }_{95}$ Comunicación, de 19 de abril de $20 \overline{16}$, de la Comisión al Parlamento Europeo, al Consejo, al Comité Económico y Social Europeo y al Comité de las Regiones: Digitalización de la industria europea: Aprovechar todas las ventajas de un mercado único digital [COM(2016) 180 final]. 
los datos y del conocimiento ${ }^{96}$; un Plan de Acción sobre Administración Electrónica de la Unión para el 2016-2020, acelerando la transformación digital de la Administración ${ }^{97}$; y la fijación de prioridades sobre la normalización de las TIC para el mercado único digital ${ }^{98}$.

Y ya en España, a la luz del más sencillo y discreto artículo 44.2 de la Constitución ${ }^{99}$ e implementando la Agenda digital europea a nivel nacional, está la Agenda Digital para España (febrero de 2013) ${ }^{100}$, en la que se recogen como objetivos: fomentar el despliegue de redes y servicios para garantizar la conectividad digital (eliminando barreras para el despliegue de redes y promover así la unidad de mercado; impulsando el despliegue de redes ultrarrápidas; buscando conseguir un uso más eficiente del espectro radioeléctrico; y mejorando la experiencia de usuario de los servicios de banda ancha); desarrollar la economía digital para el crecimiento, la competitividad y la internacionalización de la empresa española (incentivando el uso transformador de las TIC en las empresas; impulsando el comercio electrónico y la producción y distribución a través de Internet de contenidos digitales; potenciando las oportunidades para la industria electrónica; favoreciendo la internacionalización de las empresas tecnológicas; potenciando las industrias de futuro; y fortaleciendo la industria TIC, mediante el desarrollo de proyectos tecnológicos en servicios públicos); mejorar la e-Administración y adoptar soluciones digitales para una prestación eficiente de los servicios públicos (avanzando hacia una Administración integrada en la sociedad con servicios

${ }^{96}$ Comunicación, de 19 de abril de 2016, de la Comisión al Parlamento Europeo, al Consejo, al Comité Económico y Social Europeo y al Comité de las Regiones: Iniciativa Europea de Computación en Nube -construir en Europa una economía competitiva de los datos y del conocimiento [COM(2016) 178 final].

${ }_{97}$ Comunicación, de 19 de abril de 2016, de la Comisión al Parlamento Europeo, al Consejo, al Comité Económico y Social Europeo y al Comité de las Regiones: Plan de Acción sobre Administración Electrónica de la UE 2016-2020. Acelerar la transformación digital de la administración [COM(2016) 179 final].

98 Comunicación, de 19 de abril de 2016, de la Comisión al Parlamento Europeo, al Consejo, al Comité Económico y Social Europeo y al Comité de las Regiones: Prioridades de la normalización de las TIC para el mercado único digital [COM(2016) 176 final].

99 «Los poderes públicos promoverán la ciencia y la investigación científica y técnica en beneficio del interés general». Al respecto de éste, vid. GARCÍA FERnÁNDEZ, J., «Artículo 44.2. Fomento de la ciencia», en AA.VV. Comentarios a la Constitución española de 1978 (IV) (Madrid: Cortes Generales / Editoriales de Derecho Reunidas, 1996), 219234.

${ }_{100} C f r .<$ http://www.agendadigital.gob.es/agenda-digital/recursos/Recursos/1.\%20 Versi\%C3\%B3n\%20definitiva/Agenda_Digital_para_Espana.pdf> (25/04/2016). De interés, vid. SANz GIL, J., «La sociedad de la información. Convergencia tecnológica con Europa: eEurope 2010 / eEspaña 2010», Revista Universitaria Europea 15 (2011), 23 y ss. 
públicos de calidad y centrados en los ciudadanos y en las empresas; incrementando el uso de los servicios públicos electrónicos por parte de los ciudadanos y las empresas; racionalizando y optimizando el empleo de las TIC en las Administraciones Públicas; promoviendo la cooperación y la colaboración con organizaciones, empresas y agentes sociales en materia de Administración electrónica; y el empleo de la tecnología para eliminar la brecha digital); reforzar la confianza en el ámbito digital (impulsando el mercado de los servicios de confianza; reforzando las capacidades para la confianza digital; impulsando, nuevamente, la excelencia de las organizaciones en materia de confianza digital); impulsar el sistema de $\mathrm{I}+\mathrm{D}+\mathrm{i}$ en Tecnologías de la Información y las Comunicaciones (incrementando la eficiencia de la inversión pública en $\mathrm{I}+\mathrm{D}+\mathrm{i}$ en $\mathrm{TIC}$; fomentando la inversión privada en $\mathrm{I}+\mathrm{D}+\mathrm{i}$ en TIC; fomentando, otra vez, el I+D+i en TIC en pequeñas y medianas empresas; y ampliando la participación española en I+D+i en TIC en el ámbito internacional); y promover la inclusión y alfabetización digital y la formación de nuevos profesionales TIC.

Pero es en el ámbito autonómico, y en concreto tras las últimas reformas estatutarias de la década pasada, donde la informática ha pasado a tener un papel propio en la actividad pública, positivizándose expresamente (y más allá, por tanto, del mero progreso tecnológico); y es que, al margen de cuál sea el alcance jurídico de las normas estatutarias referentes a la informática (en sus diversas proyecciones), lo cierto es que los últimos Estatutos de Autonomía reformados (los llamados de segunda generación) han asumido los nuevos cambios acaecidos en la sociedad española en estos últimos años (en especial, ante la falta de reformas constitucionales), como así acontece en el vigente Estatuto de Autonomía para Andalucía (LO 2/2007, de 19 de marzo). De este modo, y a modo de objetivo básico de la Comunidad, el Estatuto andaluz prevé «la incorporación del pueblo andaluz a la sociedad del conocimiento» (art. 10.3.12. $\left.{ }^{\circ} \mathrm{EAA}\right)^{101}$; como derecho estatutario (incluso), y al margen de la protección de datos (art. $32 \mathrm{EAA})^{102}$, «se reconoce el derecho a acceder y usar las nuevas tecnologías y a participar activamente en la sociedad del conocimiento, la información y la comunicación, mediante los

101 También, si bien desde una perspectiva más genérica, art. 10.3.11. ${ }^{\circ} \mathrm{EAA}:$ «El desarrollo industrial y tecnológico basado en la innovación, la investigación científica, las iniciativas emprendedoras públicas y privadas, la suficiencia energética y la evaluación de la calidad, como fundamento del crecimiento armónico de Andalucía».

102 «Se garantiza el derecho de todas las personas al acceso, corrección y cancelación de sus datos personales en poder de las Administraciones públicas andaluzas». También, para Cataluña, art. 31 LO 6/2006; o art. 29 LO 1/2007, de 28 de febrero, de reforma del Estatuto de las Illes Balears. 
medios y recursos que la ley establezca» (art. 34 EAA) ${ }^{103}$; y como principio rector de las políticas públicas (ahora), «el acceso a la sociedad del conocimiento con el impulso de la formación y el fomento de la utilización de infraestructuras tecnológicas» (art. 37.1.15. ${ }^{\circ}$ EAA $)^{104}$.

\section{EL DERECHO CONSTITUCIONAL EN LOS TIEMPOS DEL GOOGLE SELF-DRIVING CAR}

Redactando ya estas páginas, saltaba la noticia de que los de Microsoft habían puesto en contacto un ordenador (Tay) con el público a través de las redes sociales, para ser desconectado en menos de 24 horas tras advertir que éste ¡se había vuelto nazi! ${ }^{105}$. Resulta obvio, así, que no estamos en la Era de Ultrón, pues todavía está activo el botón de desconexión; pero lo que también resulta obvio es que el experimento pone en evidencia la búsqueda de la capacidad de las máquinas para que alcancen cierta facultad no sólo de aprendizaje autónomo, sino de decisión, actuación y comunicación propia. Por supuesto que tal experimento no es el único sobre la inteligencia artificial; sin entrar en una dinámica de presentar todas (o buena parte de) las investigaciones que hoy giran en torno a la inteligencia artificial (pues sobrepasaría con creces los modestos propósitos de estas páginas) ${ }^{106}$, lo que sí podemos es identificar algún supuesto (como el señalado) al respecto (y que consideremos de particular interés). Es así que destaquemos el Google SelfDriving Car como prototipo de máquina expresa y específicamente diseñada para tomar decisiones en tiempo real y a tenor de las circunstancias cambiantes del momento ${ }^{107}$; una auténtica muestra, por tanto, de inteligencia

${ }^{103}$ Vid. Álvarez-Ossorio Micheo, F., «Artículo 34. Acceso a las tecnologías de la información y de la comunicación», en AA.VV. Comentarios Estatuto de Autonomía para Andalucía (I)... cit., 539-549.

104 Además, art. $37.1 .13 .^{\circ}$ EAA: «El fomento de la capacidad emprendedora, la investigación y la innovación». También, art. 28.2 LO 5/2007, de 20 de abril, de reforma del Estatuto de Autonomía de Aragón; art. 16.21 LO 14/2007, de 30 de noviembre, de reforma del Estatuto de Autonomía de Castilla y León; o el más reciente art. 7.12 LO 1/2011, de 28 de enero, de reforma del Estatuto de Autonomía de la Comunidad Autónoma de Extremadura.

${ }_{105}$ Cfr. <http://www.lavanguardia.com/tecnologia/internet/20160325/40672722377/ inteligencia-artificial-microsoft-nazi.html $>(14 / 04 / 2016)$.

106 Google, por su parte, con el AlphaGo, ha conseguido diseñar un software capaz no sólo de aprender, sino de imaginar; $c f r$. <http://www.elconfidencial.com/tecnologia/2016-06-20/inteligencia-artificial-google-deep-learning-redes-neuronales_1218797/> (15/08/2016).

${ }^{107}$ Cfr. <https://www.google.com/selfdrivingcar/how/> (11/04/2016). 
artificial $^{108}$, al servicio de un transporte eficiente, seguro y autónomo de personas $^{109}$. Mas con ello, también, la propuesta de drones con los que repartir mercancías, y consecuentemente la ampliación de las vías terrestres de transporte a la más abierta, cambiante y delicada y compleja zona aérea ${ }^{110}$; e incluso, la propia navegación espacial, al respecto de viajes muy prolongados en el tiempo (cómo no, Marte -como primer paso-) ${ }^{111}$. Es de este modo que, al día de hoy, al menos podamos hablar de que estemos ya en los tiempos del Google Self-Driving Car (pues decir «era» nos resulta excesivo...), al buscar ya la tecnología desarrollar sistemas informáticos inteligentes capaces de aprender y de garantizar la guía autónoma y segura de vehículos (y con ellos, de personas y mercancías); sistemas, en consecuencia, que han de tomar decisiones propias y autónomas conforme a una información cambiante en tanto que sujeta a las peculiaridades variables del instante en relación al medio y a otros vehículos y terceros; y sistemas, obviamente, que ya son objeto de programación de acuerdo a determinados parámetros tanto técnicos, como de otro tipo. Precisamente, de interés, es el estudio abierto en torno a quién y cómo debería decidir/se los parámetros en virtud del cual un vehículo inteligente habría de resolver entre diversas opciones de resultado lesivo en caso de accidente (si los poderes públicos, la propia industria o simplemente los específicos usuarios-propietarios de tales vehículos), además de la naturaleza y enunciados de dichos criterios ${ }^{112}$.

Es al hilo de dicha programación que nos planteemos qué parámetros (de los no técnicos) habrían de marcar el alcance de la inteligencia artificial desde el Derecho constitucional (y de cómo éste ha venido ya adsorbiendo el

108 Vid. Cheng, P., «Autonomous Navigation and Collision Avoidance Robot», Masters Project Paper, University of California at Berkeley, 17 de mayo de 2013, 5-6, en $<$ http://www.eecs.berkeley.edu/Pubs/TechRpts/2013/EECS-2013-102.pdf $>$ $(13 / 04 / 2016)$.

109 Hasta el punto de que la National Highway Transportation and Safety Administration (EEUU), a febrero de 2016, parecía estar cerca de reconocer los sistemas de control de inteligencia artificial de Google como driver, conforme la legislación federal; p.e. http://fortune.com/2016/02/10/google-self-driving-cars-artificial-intelligence/ (11/04/2016).

${ }^{110}$ Entre otros, los proyectos de Amazon (Prime Air) o Google X (Wing). De interés, $<$ http://www.theatlantic.com/technology/archive/2014/08/inside-googles-secret-dronedelivery-program/379306/> (19/04/2016). Otra cosa es el referido carácter delicado del espacio aéreo, lo que está planteando más inconvenientes que el caso anterior a las autoridades federales norteamericanas (FAA); p.e. <https://www.technologyreview.es/ blog/347/30900/las-nuevas-reglas-para-drones-anulan-el-sueno-de/> (19/04/2016).

111 Lejos queda, por ahora, la mítica Nostromo de Alien; pero sí que en la línea de la comentada Hal 9000, en su viaje a la luna Europa de Júpiter.

112 Cfr. Bonnefon, J.F., SharifF, A. y RaHWAn, I., «The social dilemma of autonomous vehicles», Science Vol. 352 (2016), 1573-1576. 
progreso informático). En tal sentido, y al margen del clásico de las tres leyes de la robótica de Asimov, conforme a las cuales los robots no pueden hacer daño a un ser humano o por inacción permitir que un ser humano sufra daño (además de: los robots deben obedecer las órdenes de los humanos, salvo si ello entre en conflicto con la primera ley; y los robots deben proteger su existencia siempre que esto no entre en conflicto con la primera o la segunda ley $)^{113}$, el respeto y la garantía de la dignidad de las personas y el libre desarrollo de la personalidad (art. 10.1 CE) ${ }^{114}$ debería ser un eje esencial de la programación de cualquier manifestación de la inteligencia artificial; no es sólo que las máquinas inteligentes no puedan/deban dañar a los humanos (otra cosa son, claro, los meros accidentes y cuál sea, entonces, el régimen de responsabilidad correspondiente), sino que éstas, y desde una dimensión más abierta y plural a lo humano (y por tanto, superando también la idea misma de humanidad, en cuanto que ley cero de la robótica) ${ }^{115}$, evite resultados que, abrazando cualquier tipo de integrismo, protejan a los humanos (a la humanidad) más allá de ellos mismos, y desencadenando así limitaciones para éstos y sus derechos (no sólo la vida y la integridad física, claro, sino otros derechos como la libertad física, la intimidad personal, el secreto de las comunicaciones, la inviolabilidad del domicilio, etc.). Naturalmente, la creación de sistemas inteligentes directamente dirigidos contra las personas deberían quedar prohibidos (tal como ya se plantea, por cierto, al respecto de drones autónomos con fines militares ${ }^{116}$.

También, y para poder garantizarse un control externo y humano sobre la máquina inteligente, está el que ella integre sistemas tanto de control o monitorización de su actividad, como su propia desconexión o apagado (definitivo

$113 \mathrm{Al}$ respecto, vid. GARCÍA MANRIQUe, R., «»Yo, robot» o las tribulaciones de un robot kantiano», Revista de Bioética y Derecho 9 (2007), <http://www.ub.edu/fildt/revista/pdf/RByD9_Cine.pdf $>$ (10/04/2016).

114 P.e. GUTIÉrRez Gutiérrez, I., «Dignidad de la persona y funciones del Derecho constitucional», Estudios de Deusto Vol. 59/1, (2011): 357-366. También de interés, y concretando en la tecnología: PÉREz LuÑo, A.E., «Derecho y nuevas tecnologías: impacto de la red en las libertades», Revista de la Facultad de Derecho de la Universidad de Granada 8 (2005), 227 y ss.; y/o PeÑARANDA Quintero, H.R. y Quintero de PEÑARANDA, O., «Impacto de las altas tecnologías en el Derecho de Personas», Nómadas: Revista Crítica de Ciencias Sociales y Jurídicas 27 (2010): 291 y ss.

115 Según la cual, y nuevamente con Asimov, los robots no pueden «causar daño a la humanidad o, por inacción, permitir que la humanidad sufra daño».

116 Así, p.e., vid. WEAVER, J.F., «Abhor a Vacuum: The Status of Artificial Intelligence and AI Drones Under International Law», New Hampshire Bar Journal primavera/ verano (2013), 14-21; también Gutiérrez Espada, C. y Cervell Hortal, M.J., «Sistemas de armas autónomas, drones y Derecho internacional», Revista del Instituto Español de Estudios Estratégicos 2 (2013), 27-57. 
y provisional $)^{117}$, permitiendo entonces, además, que la responsabilidad última de la acción de aquélla recaiga sobre personas: sistemas inteligentes y autónomos, pero no independientes. No en vano, y al margen de la referida dimensión activa del principio de responsabilidad (en cuanto que criterio de actuación), la responsabilidad tanto jurídica como política sigue siendo fundamentalmente a posteriori, mediante mecanismos jurídicos y políticos que buscan, si no restablecer la situación (pues puede resultar imposible), sí al menos respuestas (jurídicas y políticas) ante el daño potencial o acaecido. Y es que a lo que la inteligencia artificial no debe dar lugar, en el marco de un régimen constitucional-normativo (democrático y de Derecho), es a espacios exentos de responsabilidad jurídica ${ }^{118}$ y política. Otra cosa es, sin embrago, el déficit que de ambas responsabilidades padecemos en la actualidad respecto a la tecnología en general, dada la reducción que sobre la responsabilidad jurídico-objetiva suponen ya los llamados «riesgos desconocidos», a fin de evitar un pretendido freno material (económico) a la investigación y al progreso (en especial: a nivel privado y en relación a defectos de productos y servicios, art. 140 RDLeg. 1/2007, de 16 de noviembre, por el que se aprueba el texto refundido de la Ley General para la Defensa de los Consumidores y Usuarios y otras leyes complementarias; y a nivel público y en relación con la responsabilidad de la Administración, art. 34 L 40/2015, de 1 de octubre, de Régimen Jurídico del Sector Público) ${ }^{119}$; ¿cómo entonces admitir la incertidumbre de un riesgo potencial al respecto de la informática y la inteligencia artificial?

Lo anterior, a su vez, nos lleva nuevamente a la toma de decisiones relativas a la investigación y a la puesta en funcionamiento de máquinas y sistemas inteligentes (tanto a priori, como coetáneamente); y con esto, no sólo a la clásica cuestión de la mayor o menor participación de científicos e

117 Pues la desconexión o el apagado provisional permitiría cierta intervención del principio de precaución o cautela en situaciones de riesgo no manifestado aún (en particular, con ocasión de un potencial peligro para las personas sí advertido), de modo que la desconexión o apagado no suponga consecuencias definitivas para el sistema. Además, debería preverse, en lo posible, mecanismos sustitutivos (y/o paliativos de la desconexión o apagado, tanto definitivo como temporal), a fin evitar una situación de dependencia tecnológica tal que impidiera de facto dicha desconexión o apagado.

$118 \mathrm{Y}$ ello, en especial, a la vista del derecho fundamental a la tutela judicial efectiva (art. 24.1 CE), y otros derechos equivalentes a nivel internacional y regional, y en virtud del cual todos tenemos derecho a que se nos garantice jurisdiccionalmente cualquier derecho lesionado o puesto en peligro.

119 Por todos, vid. EsteVE PARDO, J., «La protección de la ignorancia. La exclusión de responsabilidad por los riesgos desconocidos», Revista de Administración Pública 161 (2003), 53 y ss. 
ingenieros en tales decisiones ${ }^{120}$, sino, e incluso, si una máquina inteligente podría participar en decisiones que afecten a la propia inteligencia artificial de ella misma o de otras. En cuanto a esto último, la informática y la inteligencia artificial pueden desarrollar (entendemos) un papel muy interesante en el futuro a la hora de evaluar técnicamente cuestiones tecnológicas, sobre todo a la vista del grado de incerteza (incertidumbre) con el que hoy la ciencia y la tecnología se mueven de ordinario al respecto (según se ha advertido más arriba); otra cosa es, sin embargo, dejar que una máquina inteligente pueda decidir sobre ella u otras, salvo que mantengamos el control sobre ésta (conforme también se ha señalado) a fin de poder, no sólo abortar decisiones potencial o efectivamente peligrosas, sino imputar a las personas la responsabilidad inicial y ulterior de la decisión. Lo que desde luego no cabe, entendemos, es utilizar la informática, y en su caso la inteligencia artificial, para extraer de la política (e incluso del Derecho) la toma de decisiones dada una supuesta toxicidad de ésta en relación con la materia a resolver (tal como precisamente se ha planteado en relación con la distribución de refugiados en Europa, según se ha señalado); ello sería un intento de obviar la responsabilidad (política), lo que no compartimos desde una perspectiva constitucional (según venimos advirtiendo).

Respecto a la toma de decisiones relativas a la informática y a la inteligencia artificial, la referida limitación que de la responsabilidad jurídica hoy se predica nos llevaría consecuentemente a reforzar aquélla tanto a priori, como de manera coetánea o paralela. A priori, procedimentalmente (de un lado), procurándose una intervención plural y participativa de sujetos públicos, privados y expertos (en una variabilidad, claro, dependiente del tipo de decisión a adoptar); y sustantivamente (de otro), en atención al respeto hacia los demás (principio de responsabilidad), la funcionalidad y la finalidad social y general (incluso) ${ }^{121}$, junto a los defectos o problemas detectados

${ }^{120}$ En tal sentido ya, y por ejemplo (recuérdese), la comentada Agencia de Protección de Datos, en cuanto que Administración independiente y de marcado carácter técnico. Pero también, el progresivo aumento: tanto de elementos técnicos en los actos públicos, acompañado por el progresivo aumento de la participación de peritajes, comités y órganos de asesoramiento tecnológico que ganan peso en la decisión final; como de, y simplemente, la asunción por lo público de parámetros y normas fruto de la autorregulación privada. Sobre ello, si bien con carácter general, vid. otra vez Esteve PARDO, J., «Ciencia y Derecho... cit., 63 y ss.

${ }_{121}$ Con la referida Agenda digital, finalmente, la Unión Europea parece dar respuesta, si no a un hipotético derecho de los europeos a participar en el progreso informático (lo que no tiene suficiente cobertura a nivel del Derecho originario de la Unión), sí al menos a una idea de investigación e innovación responsable (Responsible Research and Innovation) con la que garantizar cierta correspondencia entre los resultados derivados de éstas y los valores, las necesidades y las expectativas de la sociedad, fomentando la participa- 
(conocidos) o cognoscibles en potencia o bajo sospecha (en especial, con ocasión de versiones beta puestas a disposición de múltiples sujetos antes de su definitiva comercialización o apertura al público en general). Y paralela y cautelarmente cuando luego, tras la decisión inicial, se desvelan nuevos problemas o riesgos potenciales, debiéndose resolver lo más pronto posible, e incluso llegándose excepcionalmente a suspender la actividad (en atención al tipo y grado del daño o riesgo detectado), en su caso (a modo de adaptación blanda del principio de precaución, ahora), y en tanto se resuelve definitivamente la materialización o no del riesgo.

\section{CONSIDERACIONES FINALES SOBRE LA INTELIGENCIA ARTIFICIAL Y EL DERECHO CONSTITUCIONAL}

Insistimos, no estamos en la Era de Ultrón, pero sí que puede que estemos ante ella, en cuanto que potencial riesgo a evitar; somos, finalmente, conscientes de su posibilidad (aunque hipotética), y nuestra responsabilidad, constitucional, es impedirlo. Ahora bien, lo anterior no ha de llevarnos, sin más, a negar desde el Derecho constitucional la inteligencia artificial, sino a, siendo conscientes de los riesgos a los que ella puede dar lugar, colaborar a encauzar su desarrollo de modo que ésta quede dentro de lo constitucionalmente posible y lo postulado o promovido por unos y otros (siempre principio democrático, y en particular en su dimensión pluralista); gestión del riesgo, al fin y al cabo ${ }^{122}$, desde el marco constitucional. Y todo esto (y conforme lo planteado antes):

- Procurando un concepto propio de la inteligencia artificial desde el Derecho público, pues no es positivo (según hemos advertido en anteriores trabajos) que el Derecho (y por tanto el Derecho constitucional) se limite a actuar siempre a rebufo del progreso tecnológico, ya que en tal caso la tecnología (la informática y la inteligencia artificial, para estas páginas) resulta en una posición de predominio sobre el pulso existente entre ella y el Derecho público (y la Constitución), a la par que el Derecho pierde su dimensión racional-normativa. La única forma de romper esa dinámica es, dentro de los márgenes técnicos que

ción de sujetos privados (empresas y ONG), como de instituciones y centros públicos científicos y universitarios: así, el programa trasversal Ciencia con y para la Sociedad (2013-2020); y con esto, parecería, cierta delimitación del progreso informático en el seno de la Unión desde el principio de responsabilidad. Vid. Osset HernÁndez, M., «Responsible Research and Innovation (RRI): la próxima frontera en I+D», Revista Lasallista de Investigación Vol. 11/1 (2014): 51-55.

122 Acerca de ésta, $c f r$. EsteVE PARDO, J., «Ciencia y Derecho ante los riesgos para la salud. Evaluación, decisión y gestión», Documentación Administrativa 265-266 (2003): 146 y ss. 
supone siempre abarcar jurídicamente conceptos inicialmente tecnológicos y mutables (a tenor de su evolución), alcanzar cierta concepción jurídica (no sólo tecnológica) de la informática y de la inteligencia artificial desde el Derecho público, aunque sea provisional, genérica y apriorística $^{123}$.

- Desde la anterior idea, planteándonos entonces quiénes y cómo se deba decidir sobre cuestiones que afecten a la inteligencia artificial; y ello, buscando abarcar tanto el elemento técnico del objeto, como el principio democrático y la garantía del pluralismo y las minorías. Y al hilo de esto, y al tiempo, la articulación además de instrumentos de exigencia de efectiva responsabilidad a posteriori, incluyendo su dimensión más política.

- Hablando de responsabilidad no se ha de olvidar, por otra parte, su dimensión previa, en cuanto que principio jurídico desde el que orientar el progreso tecnológico, y por tanto el informático y la misma inteligencia artificial; recuperar así el deber actuar neokantiano tanto al respecto del desarrollo de la investigación, como luego en relación con los parámetros que han de integrar la programación base de una inteligencia artificial.

- Previendo los conflictos constitucionales que al tiempo pueda ir suponiendo la inteligencia artificial, a fin de resolverlos y encauzarlos constitucionalmente. Desde la dimensión apriorística antes señalada, se ha de mantener el pulso de la tensión entre el Derecho y la informática (de un lado), de manera que podamos reabsorber el conflicto con el menor daño posible (tanto en relación con los bienes jurídicoconstitucionales, como al propio progreso informático); e incluso, diseñando mecanismos de resolución de dichos conflictos lo más efectivos posible (de otro lado).

- Advirtiendo también la prohibición y limitación de manifestaciones de la inteligencia artificial contrarias a principios y bienes de la máxima relevancia constitucional; y de esta manera potenciando la dimensión político-normativa del Derecho constitucional, frente a la meramente judicial y conflictual que hoy tiende a prevalecer en el contexto de la globalización ${ }^{124}$.

${ }^{123}$ Sobre la necesidad de un concepto constitucional acerca de la más genérica tecnología (a los anteriores efectos), vid. SÁNCHEZ BARRILAO, J.F., «Sobre la Constitución normativa y la tecnología», Revista de la Facultad de Derecho de la Universidad de Granada 8 (2005), 257 y ss., y en especial p. 261.

${ }^{124} C f r$. otra vez Sánchez BarRiLaO, J.F., pero ahora «Reivindicando la ley», en AA.VV. Constitucionalismo crítico. Libre amicorum Carlos de Cabo Martín (II), 2. ${ }^{\text {a ed. }}$ (Valencia: Tirant lo Blanch, 2016), 878-883, y 908-913. 
- Al amparo de tal contexto globalizado (precisamente), extender el objeto jurídico «informática e inteligencia artificial» a ámbitos supraestatales, de manera que las respuestas constitucionales alcanzadas sean capaces de regular y resolver de manera cierta una realidad esencialmente virtual y que escapa de la acción física y clásica de los Estados; y en tal sentido, efectivamente, la propia configuración de internet (red, además, en la que conectar sistemas inteligentes), como paradigma de la necesidad de regulación supraestatal ${ }^{125}$.

- Advertida asimismo la dimensión positiva de la informática para el Derecho constitucional (al respecto de las relaciones entre los ciudadanos y los poderes públicos, y especialmente en cuanto a políticas sociales), abriendo la Constitución, en su caso (pero desde luego el más genérico Derecho público), a potenciales efectos positivos de la inteligencia artificial sobre la misma, más allá del por sí relevante valor constitucional que supone el mero progreso social, económico y cultural que pueda impulsar la inteligencia artificial.

- Y finalmente, claro, contribuir a proyectar tal fomento de la informática y de la inteligencia artificial conforme a la dignidad de la persona (y de los demás principios y derechos y libertades que de ella se derivan), y en post del más genérico progreso humano ${ }^{126}$.

TITLE: Constitutional law in the age of Ultron: information technology and artificial intelligence as a constitutional object

RESUMEN: Este trabajo tiene como objeto los retos del Derecho constitucional al respecto de la informática, en general, y de la inteligencia artificial, en especial. Los riesgos que para la humanidad ya se predican en relación con la inteligencia artificial exigen de los constitucionalistas que afronten tal cuestión. Siguiendo la estela de la ciencia ficción, nos planteamos cómo abordar constitucionalmente evitar los riesgos que para la humanidad puede suponer la inteligencia artificial, pero ello sin obviar su potencial dimensión positiva para el progreso humano. En este sentido, se parte de la experiencia constitucional existente sobre la tecnología y la informática, para luego concretar en la inteligencia artificial.

PALABRAS CLAVE: Derecho constitucional, progreso informático, inteligencia artificial.

ABSTRACT: This paper aims the Constitutional law challenges on the grounds of computing, and especially about artificial intelligence. The

125 P.e. Muñoz Machado, S., La regulación de la red (Poder y Derecho en Internet) (Madrid: Taurus, 2000), 42 y ss.

${ }^{126}$ Nuevamente, arts. 27.1, in fine, DUDH y 15.1.b PIDESC. 
risks for humanity predicted in relation to artificial intelligence demand constitutional science to deal with this question. Following science fiction, we consider how to avoid possible risks for humanity from artificial intelligence from a constitutional point of view, keeping in mind its potential positive dimension to human progress. In this sense, this paper considers the constitutional experience on technology and computers in order to focus on artificial intelligence.

KEY WORDS: Constitutional Law, computing progress, artificial intelligence.

RECIBIDO 07.10.2016

ACEPTADO: 19.12.2016 